\title{
Laccases in food processing: Current status, bottlenecks and perspectives
}

\author{
Emanueli Backes ${ }^{\text {a }}$, Camila Gabriel Kato ${ }^{\text {b,c }}$, Rúbia Carvalho Gomes Corrêa ${ }^{\text {d,e }}$, \\ Regina de Fátima Peralta Muniz Moreira ${ }^{\mathrm{f}}$, Rosely Aparecida Peralta ${ }^{\mathrm{g}}$, Lillian Barros ${ }^{\mathrm{e}}$, Isabel C.F. \\ R. Ferreira ${ }^{\mathrm{e}}$, Gisella Maria Zanin ${ }^{\mathrm{b}, \mathrm{h}}$, Adelar Bracht ${ }^{\mathrm{a}, \mathrm{i}}$, Rosane Marina Peralta ${ }^{\mathrm{a}, \mathrm{i}, *}$ \\ ${ }^{a}$ Postgraduate Program in Food Science, Universidade Estadual de Maringá, Brazil \\ b Postgraduate Program in Chemical Engineering, Universidade Estadual de Maringá, Brazil

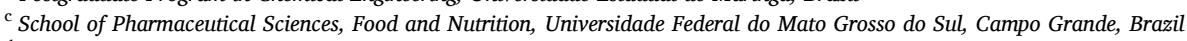 \\ d Program of Master in Clean Technologies, Cesumar Institute of Science Technology and Innovation (ICETI), Cesumar University - UniCesumar, Brazil \\ ${ }^{\mathrm{e}}$ Mountain Research Centre (CIMO), Polytechnic Institute of Bragança, Portugal \\ ${ }^{\mathrm{f}}$ Department of Chemical and Food Engineering, Universidade Federal de Santa Catarina, Brazil \\ ${ }^{\mathrm{g}}$ Department of Chemistry, Universidade Federal de Santa Catarina, Brazil \\ ${ }^{\text {h }}$ Department of Chemical Engineering, Universidade Estadual de Maringá, Brazil \\ ${ }^{i}$ Department of Biochemistry, Universidade Estadual de Maringá, Brazil
}

\section{A R T I C L E I N F O}

\section{Keywords:}

Laccases

Food processing

Antioxidant activity

Antimicrobial activity

Covalent crosslinking

\begin{abstract}
A B S T R A C T
Background: Laccases (benzenediol:oxygen oxidoreductases, EC 1.10.3.2) catalyze the oxidation of a wide variety of organic and inorganic substrates, typically $p$-diphenols with a concomitant reduction of oxygen $\left(\mathrm{O}_{2}\right)$ to water. Several molecules naturally occurring in foods and beverages (e.g., phenols, carbohydrates, unsatured fatty acids and thiol-containing proteins) can be modified by laccases. Hence, the interaction between laccase and these molecules can and has been widely explored by the food industry for various technological purposes.

Scope and approach: The present work aims at providing a critical review on the current uses of laccases in food processing, at discussing the main bottlenecks for its popularization, and at presenting future perspectives. Both scientific reports and patents, covering preferably the last five years, were considered.

Key findings and conclusions: Several traditional uses of laccases in food processing including baking, beverage, and dairy industries were detailed. Special efforts were developed, however, in analyzing future perspectives. The latter includes the application of laccases in the synthesis of new compounds with functional properties, such as antioxidant and antimicrobial activities. No less attention was devoted to the recent developments in the field of crosslinking of polymers, such as proteins and polysaccharides. Scaling up of the production of the laccase itself and especially of the novel products derived from its applications in the food sector will be essential for cost reduction and, consequently, for market expansion.
\end{abstract}

\section{Introduction}

Laccases (benzenediol:oxygen oxidoreductases, EC 1.10.3.2) are multi-copper oxidases that have a functional unit consisting of four coppers (a type- 1 , a type- 2 and two type- 3 coppers). Laccases catalyze the oxidation of a wide variety of organic and inorganic substrates, typically $p$-diphenols with a concomitant reduction of oxygen $\left(\mathrm{O}_{2}\right)$ to water (Chauhan, Goradia, \& Saxena, 2017; Janusz et al., 2020; Mate \& Alcalde, 2015, 2016). Laccases are widely distributed in nature and have been described in plants, insects, bacteria, and fungi. Their physiological functions differ depending on the organism (Janusz et al., 2020; Su, Fu,
Wang, Silva, \& Cavaco-Paulo, 2018).

Plant laccases are primarily involved in lignin polymerization, one of the most important plant cell wall biopolymer (Mogharabi \& Faramarzi, 2014; Wang et al., 2015). Laccases have also been detected in members of several insect genera, such as Bombyx, Calliphora, Diploptera, Drosophila, Lucilia, Menduca, Musca, Oryctes, Papilio, Phormia, Rhodnius and Sarcophaga (Janusz et al., 2020). Cuticle sclerotization is the main biological function in this class of organisms (Sharma, Jain, Jain, Kidwai, \& Kuhad, 2018).

Bacterial laccase activity was firstly detected in 1993 in Azospirillum sp. from rice rhizosphere. Since then, laccases have been discovered in

\footnotetext{
* Corresponding author. Postgraduate Program in Food Science, Universidade Estadual de Maringá, Brazil.

E-mail address: rmperalta@uem.br (R.M. Peralta).
} 
and produced from several bacteria genera, e.g., Geobacillus, Streptomyces, Rhodococcus, Staphylococcus, Azospirillum, Pseudomonas, Delfia, Enterobacter and Proteobacterium, Gram-positive bacteria being the main producers (Chauhan et al., 2017; Guan, Luo, Wang, Chen, \& Liao, 2018). Bacterial laccases exert important biological functions in morphogenesis and copper ion homeostasis (Polak \& Jarosz-Wilkolazka, 2012), synthesis of brown pigments in spores and protection against ultraviolet light and hydrogen peroxide (Janusz et al., 2020).

Fungal laccases have already been isolated from numerous species of various groups, e.g., Ascomycetes, Deuteromycetes and Basidiomycetes spp. (Su et al., 2018). They play important role in spore resistance and pigmentation, and have been associated with humus turnover, detoxification process (Upadhyay, Shrivastava, \& Agrawal, 2016) and lignin biodegradation (Wang et al., 2015). The majority of the laccases characterized so far have been derived from white rot fungi, which are efficient lignin degraders (Kadri et al., 2017). Agaricus bisporus (J.E. Lange) Imbach, Botrytis cinerea Pers., Bjerkandera adusta (Willd.) P. Karst. Coprinus cinereus (Schaeff.) Gray, Ganoderma lucidum (Curtis) P. Karst., Pleurotus ostreatus (Jacq.) P. Kumm., Pleurotus pulmonarius (Fr.) Quél., Rigidoporus lignosus (Klotzsch) Imazeki and Trametes versicolor (L.) Lloyd are examples of basidiomycetes that produce laccases (Manavalan, Manavalan, Thangavelu, \& Heese, 2013; Viswanath, Rajesh, Janardhan, Kumar, \& Narasimha, 2014; Wang et al., 2019).

Since the 90 s of the last century, the interest about laccases has substantially increased, and more than 4000 scientific papers on this theme, encompassing several knowledge domains, have been published during the last 5 years (obtained from Web of Science, October 2020). The majority of these articles have addressed the application of laccases in the environmental and bioenergy areas. Particularly, laccases have been extensively studied as a green alternative for pre-treatment of ligncellulosic residues ( 270 articles in the last 5 years using the terms laccase plus pretreatment) and for degradation/modification of xenobiotics (359 articles in the last 5 years using the terms laccase plus environment). However, in recent years, the use of laccases in food processing has received increasing attention (Moreno, Ibarra, Eugenio, \& Tomás-Pejó, 2020; Mukesh, Nirmala, \& Amit, 2018).

Enzyme-mediated processes are considered clean technologies as they allow waste prevention, minimization of the use of toxic solvents/ reactions, energy efficiency, use/recovery of renewable materials (e.g. agroindustrial residues) and safer methods (Andreus, Silva, \& Ferreira-Leitão, 2016; Giacobbe, Pezzella, Lettera, Sannia, \& Piscitelli, 2018; Nizami et al., 2017). In this context, several molecules naturally occurring in foods and beverages (e.g., phenols, carbohydrates, unsatured fatty acids and thiol-containing proteins) can be modified by laccases. Hence, the interaction between laccase and these molecules can be widely explored by the food industry for various technological purposes. For instance, laccases can be used for the improvement of food sensory parameters, to promote odor control, taste enhancement and new functionalities, or to reduce the number of undesired products in food products, among other possibilities (Forootanfar \& Faramarzi, 2019). More recently laccases have been used in the crosslinking of polymers, such as proteins and polysaccharides, an intervention that can introduce substantial modifications in the properties of foods ( $\mathrm{Li}$ et al., 2021). Not least, expanding the use of enzymes in general is essential for the development of sustainable technologies in food industry. To the best of our knowledge, all these topics have not yet been approached in a single text. Considering their importance, however, the present work aims to provide a critical review on the current use of laccases in food processing. Besides describing the new developments, the text discusses the main bottlenecks for their application and popularization, and presents an overwiew on the future perspectives. Efforts have also been done in discussing the possible costs of the practical application of the new developments. In order to address trends on this topic, research papers and patents published/registered after 2015 were preferably considered.

\section{Structural characteristics of laccases}

Laccases are globular proteins belonging to the multi-domain cupredoxin family (Polyakov et al., 2017). These enzymes can be monomeric, dimeric or tetrameric glycoproteins and their molecular weight ranges from 20 to $130 \mathrm{kDa}$, depending on the organism (Agrawal, Chaturvedi, \& Verma, 2018; Senthivelan, Kanagaraj, \& Panda, 2016; Zerva, Simic, Topakas, \& Nikodinovic-Runic, 2019). Most bacterial laccases present molecular weights ranging from 20 to $80 \mathrm{kDa}$, whereas most fungal laccases present molecular weights ranging from 50 to $80 \mathrm{kDa}$ (Zerva et al., 2019).

The molecular architecture of the laccases generally consists in three cupredoxin domains with a $\beta$-barrel structure. However, laccases with two domains of this type have been reported (Zerva et al., 2019). The catalytic center of laccases contains four copper ions, classified as type 1 , 2 and 3 (T1, T2 and T3, respectively), and arranged in two different substrate-binding sites. The mononuclear copper-binding site $\mathrm{T} 1$ is composed of one $\mathrm{T} 1$ copper ion and the trinuclear copper-bidding is a cluster composed by one T2 and two T3 copper ions (Reiss et al., 2013; Sekretaryova, Jones, \& Solomon, 2019; Zerva et al., 2019). These copper ion classifications are based on their electron paramagnetic resonance (EPR) features and spectroscopic properties (Gabdulkhakov et al., 2019; Polyakov et al., 2017; Sekretaryova et al., 2019).

Type 1 copper atom presents trigonal coordination with two histidine and one cysteine equatorial residue (Agrawal et al., 2018). It also has one variant axial ligand, which in bacterial and plant laccases is often methionine, whereas in fungal laccases the ligands are either leucine or phenylalanine (Mate \& Alcalde, 2015; Zerva et al., 2019). The $\mathrm{T} 1$ copper shows strong EPR signals and intense absorption at $600 \mathrm{~nm}$ associated with the covalent copper-cysteine bond (Mogharabi \& Faramarzi, 2014).

Type 2 copper is coordinated by two histidine residues (Polyakov et al., 2017). It does not absorb in the visible spectrum but its EPR spectrum reveals paramagnetic properties (Agrawal et al., 2018). The laccase active center contains two type 3 copper ions, forming a binuclear center without EPR signals and absorption at $330 \mathrm{~nm}$ when oxidized (Agrawal et al., 2018; Mogharabi \& Faramarzi, 2014). The T3 coppers have three histidine ligands each and are separated by a hydroxide bridge. The T1 mononuclear site is located 12 amino acid residues away from the T2/T3 trinuclear cluster, and each T3 copper is 4 residues away from the T2 copper (Mogharabi \& Faramarzi, 2014).

\section{Mechanism of action and properties of laccase}

The laccase mediated reaction consists in a four one-electron substrate oxidation and its transfer to the dioxygen, yielding two water molecules as by-product (Polak \& Jarosz-Wilkolazka, 2012; Reiss et al., 2013; Forootanfar \& Faramarzi, 2015). The free radical formed will undergo further reactions, e.g., amination, oxidation, cyclization, dimerization or polymerization, until a final and more stable product is formed (Fig. 1) (Forootanfar \& Faramarzi, 2015; Kudanga, Nemadziva, \& Roes-Hill, 2017; Mogharabi \& Faramarzi, 2014).

The catalytic cycle begins with a monoelectronic reduction of a substrate at the $\mathrm{T} 1$ site. This produces an oxidized form of the substrate and a reduction of the $\mathrm{T} 1 \mathrm{Cu}(\mathrm{II})$ to $\mathrm{Cu}(\mathrm{I})$. In a subsequent step the electrons are internally transferred through a Cys-His pathway to the trinuclear T2/T3 copper cluster (Polak \& Jarosz-Wilkolazka, 2012; Solomon, 2016), where molecular oxygen is reduced to water (Polak \& Jarosz-Wilkolazka, 2012; Solomon, Augustine, \& Yoon, 2008) (Fig. 1).

Laccases are able to oxidize many compounds, but its oxidation efficiency depends on the difference between the redox potentials of the T1 copper and the substrate (Polak \& Jarosz-Wilkolazka, 2012). Laccases can show a large range of redox potentials, depending on their type, organism from which they have been isolated and medium $\mathrm{pH}$ (Munk, Sitarz, Kalyani, Mikkelsen, \& Meyer, 2015). Based on the redox potential of the $\mathrm{T} 1$ site, referred to the normal hydrogen electrode 


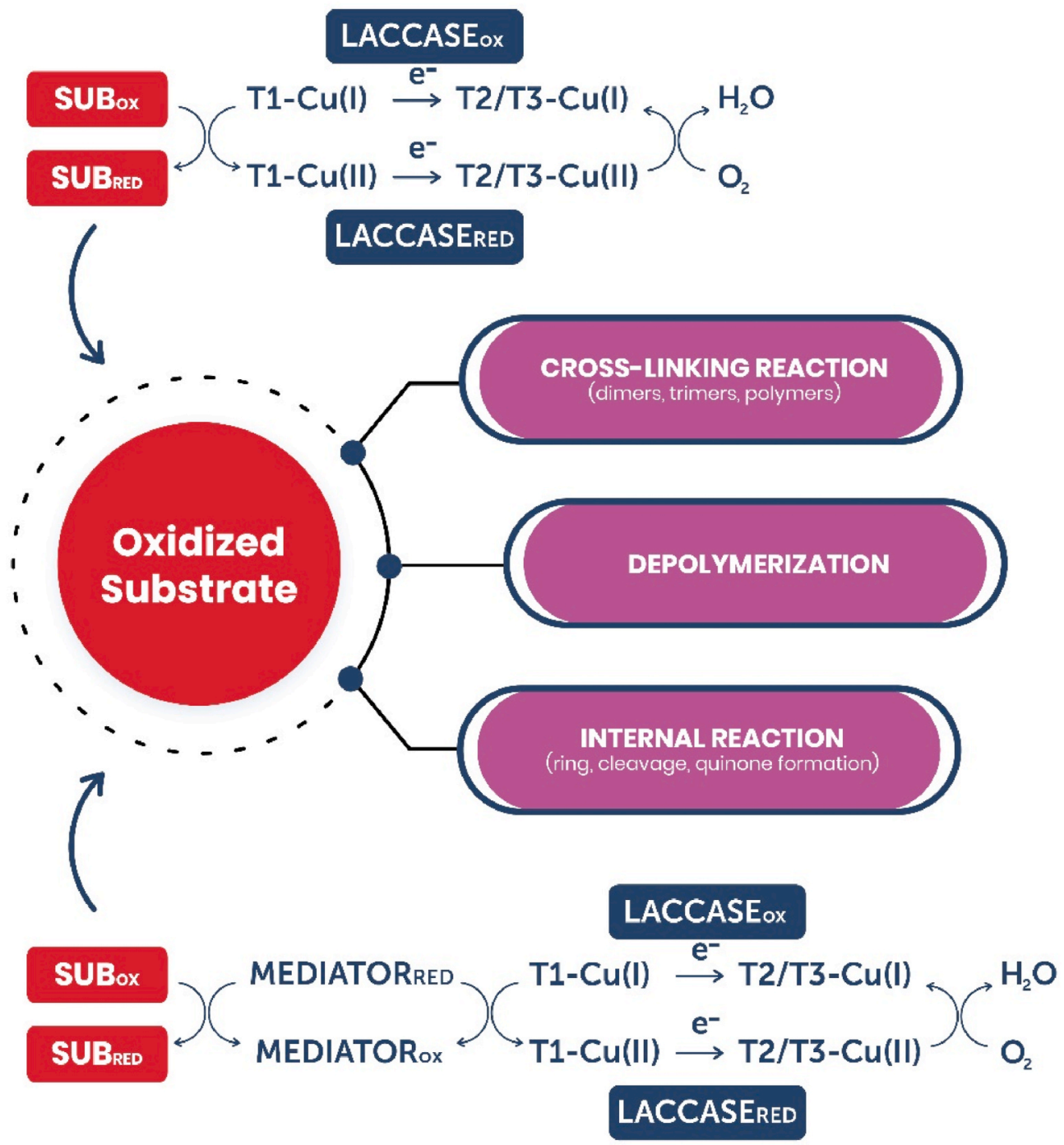

Fig. 1. The substrate oxidation reaction of the laccase, with or without mediator, producing a radical that undergoes further non-enzymatic transformations.

potential, the classification into high $(730-780 \mathrm{mV})$, middle $(470-710 \mathrm{mV})$ and low $(340-490 \mathrm{mV})$ redox potential laccases is usually accepted (Mogharabi \& Faramarzi, 2014). Bacterial and plant laccases situate often within the low redox group, while fungal laccases belong to the middle or high redox group. To be remarked is that laccases with high redox potentials are mostly produced by basidiomycetes white-rot fungi. This feature enables oxidation of substrates with a much higher redox potential and increases industrial applications in several fields (Mate \& Alcalde, 2015).

Phenols, such as mono or diphenols and their derivates, are typical substrates of laccases mediated oxidation because of their low redox potential (from 500 to 1,000 mV) (Polak \& Jarosz-Wilkolazka, 2012; Legerská, Chmelová, \& Ondrejovič, 2016). Nevertheless, laccases are often not capable of oxidizing certain substrates in a direct way due to their large size, low rate of diffusion into the enzyme active site, or high redox potential (Pogni, Baratto, Sinicropi, \& Basosi, 2015; Chauhan et al., 2017). In these cases, enzymatic reactions can be carried out in the presence of an appropriate small-sized and low molecular-weight compound called mediator (Vallecillos, Sadef, Borrull, Pocurull, \& Bester, 2017). The mediator usually contains specific functional groups (-NO, $-\mathrm{NOH},-\mathrm{HRNOH}$ ) and mediates electron transfer from the substrate to the enzyme (Polak \& Jarosz-Wilkolazka, 2012) (Fig. 1). An ideal mediator is capable of producing a stable radical, carrying out several oxidation cycles without degradation and without influencing the funcitonality of the enzyme (Mogharabi \& Faramarzi, 2014).

ABTS (2,2'-azino-bis(3-ethylbenzothiazoline-6-sulfonicacid)) was the first artificial compound explored as laccase mediator (Upadhyay et al., 2016), and its development aimed to solve problems associated with wood pulp bio-bleaching (Mogharabi \& Faramarzi, 2014). So far, compounds with a $\mathrm{N}-\mathrm{OH}$ group have been recognized as the most effective mediators, such as violuric acid, N-hydroxy-N-phenyl acetamide, N-hydroxybenzotriazole and 2,2,6,6-tetramethylpiperidin-1-yloxy (TEMPO) (Chauhan et al., 2017). However, some phenolic compounds are naturally occurring laccase mediators, e.g., ferulic acid, acetosyringone, acetovanillone and p-coumaric acid (Mogharabi \& Faramarzi, 2014).

The fact that the presence of a mediator increases the number of compounds that can be oxidized by the laccases also amplifies the perspectives of biotechnological applications (Kadri et al., 2017; Zerva et al., 2019). Currently, a successful use of the laccase-ABTS system in the degradation of wastewater synthetic dyes has been reported (Kamani, Safari, G, Asgari, \& Ashrafi, 2018; Mehrabian, Kamani, Safari, Asgari, \& Ashrafi, 2018), as well as of fragrances (Vallecillos et al., 2017) and antibiotics (Navada \& Kulal, 2019). TEMPO was effectively used as mediator in a laccase oxidation system to increase chitosan's functionality (Silva, Krolicka, van den Broek, Frissen, \& Boeriu, 2018) and also to prepare cellulose nanofibers for the paper industry (Jiang et al., 2017). Presently applications are going well beyond the already 
recognized mediators. For example, potassium hexacyanoferrate (II) trihydrate was reported to behave as an efficient redox mediator in the polymerization of aniline monomers into polyaniline. The latter is used as an antistatic electrode coating material for batteries (Shim, Noro, Cavaco-Paulo, Silva, \& Kim, 2019).

\section{Application of laccases in food processing}

\subsection{Basic principles and examples of reactions}

Sustainability, high efficiency and eco-friendly processing are concepts largely explored and adopted in food industries (Upadhyay et al., 2016). In alignment with these concepts there are four main reasons that explain the increased interest in the application of laccases in different areas of food processing. All of them fit well into the energy-saving and biodegradable features of these biocatalysts.

The first reason is that laccases are essentially green catalysts. This is because unlike other peroxidases, which use peroxides such as hydrogen peroxide $\left(\mathrm{H}_{2} \mathrm{O}_{2}\right)$ as the electron acceptor in the oxidation of a variety of organic and inorganic compounds, laccases use molecular oxygen as the final electron acceptor, releasing only water as by-product (Muñiz-Mouro et al., 2018).

Second, the capability of laccases, especially those from fungi and bacteria, to oxidize lignin, a component of lignocellulosic materials, makes them suitable for being used in pretreatments aiming at the valorization of agro-food wastes (Amin, Khorshidi, Shojaei, Rezaei, \& Faramarzi, 2018; Giacobbe et al., 2018; Patel, Shahane, Shivam, Majumdar, \& Mishra, 2019). Therefore, laccases fit well into circular economy processes, which endorse the approach to recycling and reuse, thus closing the product life cycle (Liguori \& Faraco, 2016). This concept, as discussed in details in recent reviews that focuse on the subject (Mayolo-Deloisa, González-González, \& Rito-Palomares, 2020; Roth \& Spiess, 2015), is presently gaining widespread support from researchers, enterprises and governmental agencies.

The third reason is that laccases exhibit an extraordinary capability of oxidizing a wide range of substrates, including phenols, polyphenols, anilines, aryl diamines, methoxy-substituted phenols, hydroxyindols, benzenethiols, and inorganic/organic metal compounds. Laccases are also capable of oxidizing various aromatic compounds, producing highly reactive intermediate radicals that bind through dimerization and trimerization (Mogharabi \& Faramarzi, 2014). The interest in the organic synthesis of dimers and trimers of phenolic compounds using enzymatic reactions steadily increases due to the continuous production of new compounds with functional properties.

Finally, several studies have proven the importance of laccases in the formation of cross-linking between polymers such as proteins and polysaccharides and phenolic compounds improving or altering the functional properties of polymers (Li et al., 2020, 2021; Sato, Perrechil, Costa, Santana, \& Cunha, 2015; Tian et al., 2021; Vuillemin et al., 2020). Cross-linking can occur via aromatic groups present in proteins or carbohydrates or through certain amino acid moieties present in proteins.

\subsection{Laccases in the baking industry}

The baking industry makes use of a wide range of enzymes to improve bread flavor, volume, texture, volume and freshness along shelf life. Hereupon, laccases have been applied as an additive that improves volume, texture, flavor and freshness of bakery products for several years (Minussi, Pastore, \& Duran, 2002; Arnaut, Dauvrin, Contreras, Vanneste, \& Viaene, 2006; Selinheimo, Kruus, Buchert, Hopia, \& Autio, 2006; Agrawal et al., 2018) (Fig. 2). Recently, laccases were used for improving the dough elastic properties of gluten-free flour (Manhivi, Amonsou, \& Kudanga, 2018; Taihua, Mengmei, Miao, Jingwang, \& Hongnan, 2015). Manhivi et al. (2018) reported that the laccase-mediated oxidation of amadumbe dough caused a decrease in phenolic and thiol groups, due to cross-linking of proteins and polysaccharides esterified with phenolics. Moreover, carbon dioxide was retained during proofing, ensuring the improvement in the elastic properties of the laccase-treated dough. The enzyme has also been applied to catalyze the polymerization and cross-linking of potato protein, so that smaller protein molecules form large protein conjugates (Taihua, Mengmei, et al., 2015). Thus, an enhancer was developed for improving the fermenting property of mucedin-free dough.

\subsection{Laccases in the beverage industry}

In the beverage industry, the polyphenols in the fruit are responsible for large spectrum of nutritional and therapeutic benefits. However, these compounds can interact with proteins resulting in the formation of sediments or haze, causing turbidity, aroma and flavor alteration,

\section{Laccases in Food Technology}

\section{Current uses:}
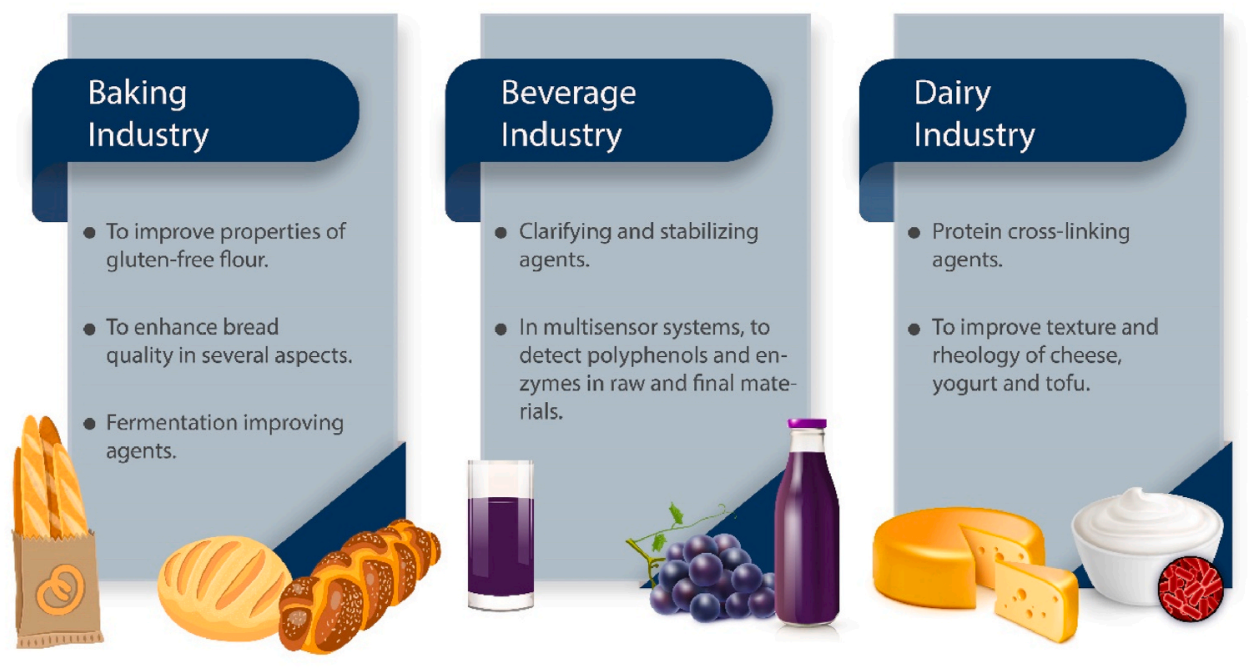

Fig. 2. Current applications of laccases in the food industry. 
affecting product quality, and reducing, thus, the shelf life of the final product (Agrawal et al., 2018; Lettera et al., 2016; Pezzella, Guarino, \& Piscitelli, 2015; Ribeiro, Henrique, Oliveira, Macedo, \& Fleuri, 2010). To overcome such technological shortcommings several researchers have indicated the use of laccases as stabilizing agents, due to their ability to oxidize most of the phenols within the beverage (Gassara-Chatti et al., 2013; Minussi et al., 2002, 2007; Neifar et al., 2011; Tanrioven \& Eksi, 2005; Yin, Ye, Kuang, Guan, \& You, 2017). Recently, Zrinski et al. (2020) described the effective potential of a biosensor based on immobilized laccase, with a screen-printed carbon electrode support modified with graphene nanoplatelets and gold nanoparticles for the amperometric detection of phenolic compounds. This simple laccase biosensor presented excellent electro-catalytic activity towards the oxidation of hydroquinone, fast response and suitable linear range for evaluation of the phenolic antioxidant capacity in real samples.

A multisensory system was developed using the Langmuir-Blodgett technique containing two phenol oxidases (laccase and tyrosinase) to detect phenolics and two enzymes (glucose oxidase and D-fructose dehydrogenase) to detect sugars (Medina-Plaza et al., 2016). The multisensory system was constructed for discriminating musts prepared from different varieties of grapes and grapes harvested in different vintages. Furthermore, it should also allow monitoring the ripening of grapes for harvesting them according to their phenolic and sugar contents. The array of biosensors proved to be able to discriminate five varieties of grapes according to their phenolic composition and sugars and was also able to monitor the ripening of grapes from veraison to harvesting. Thus, this multisensory system can be used to predict the appropriate date to initiate harvest. In a pioneer study an innovative enzyme immobilization technique was developed using matrix assisted pulsed laser evaporation in the development of a laccase-based biosensor for the determination of phenolic compounds. The authors claimed to have found a good fabrication reproducibility, stability of response and selectivity toward interferents. The method proved its usefulness in the determination of total phenolics in real matrices (Verrastro et al., 2016).

Free and immobilized laccases have been used with the purpose of juice clarification. A Trametes versicolor laccase was immobilized on a low-cost support (natural fibers from green coconut husk) and used in the clarification of apple juice (Bezerra, Bassan, Santos, Ferraz, \& Monti, 2015). The authors reported excellent results in the re-usability of the enzyme. A recombinant POXA1b laccase from Pleurotus ostreatus was immobilized on epoxy activated poly(methacrylate) beads and used in fruit juice clarification (Lettera et al., 2016). The treatment with immobilized laccase improved the sensory profile of the juice thanks to the reduction of the vinyl guaiacol concentration, a compound described as having a spicy/peppery aroma and which is considered a potent off-flavor. A similar improvement in the sensory profile of plant juices was obtained when an immobilized recombinant laccase from Bacillus atrophaeus Nakamura, expressed in Escherichia coli onto magnetic nanoparticles, was used for the removal of phenolics with consequent clarification of banana pseudo-stem juice, sorghum stem juice, and apple fruit juice (Narnoliya, Agarwal, Patel, \& Singh, 2019). A laccase from the fungus Abortiporus biennis (Bull.) Singer J2 was purified and used for oxidizing soluble phenolic compounds in the clarification of litchi juice (Yin et al., 2017). Recently, a new combination of laccase catalysis and microfiltration was developed for the juice clarification (Wang, Owusu-Fordjour, Xu, Ding, \& Gu, 2020). Laccase from Trametes versicolor was immobilized on metal-chelated magnetic silica nanoparticles and used for continuous juice clarification in a magnetically stabilized fluidized bed (MSFB) assisted by an alternating magnetic field.

Potentially useful processes in the beverage industry have often been protected by inventors through patenting. One such patent refers to a method for clarifying grape juice to produce wine in which the polyphenols undergo oxidation and polymerization catalyzed by laccase with a subsequent ease in removal by clarification (Linlin, Song, Li, Huiyan, \& Hongyu, 2017). In this method, the laccase can oxidize polyphenols to produce polyphenol oxides. The latter can repolymerize themselves to form large particles which can, in turn, be trapped in ultrafiltration membranes, what fulfils the purpose of purifying the beverages. It is claimed that the grape juice clarification method of the invention has the specificity of using laccase to treat the grape juice, has no violent effect on the wine's organoleptic characteristics and even improves its stability. The action of the laccase on the grape juice removed $50 \%$ of the total polyphenols. According to the inventor, this method is superior to physical and chemical treatment methods in terms of specificity and stability of action.

Another similar patent using rose dry white wine was developed applying the enzyme laccase in its production (Fulin, 2017). This product is made from dry white wine and rose flowers. Combined percentages of laccase and diatomite are used to discolor the rose flower jam. This is only possible due to the removal of the large amounts of phenols and anthocyanidins of the rose flower jam. This is a case in which the fragrance components and functional substances of the rose flower are preserved thanks to the combination of enzymolysis with low-temperature extraction technologies such as microwaves, ultrasound and high-pressure pulsed electric field.

\subsection{Laccases in the dairy industry}

One of the main challenges of the dairy industry is improving the texture of fermented milks, such as yoghurt, mainly because they are sensitive to shear and consequently suffer structural losses. In this sense, Struch et al. (2015) proposed to improve the viscoelastic properties of skimmed milk yoghurt through treatment with laccase and the results turned out to be a great alternative to improve yoghurt texture. Posteriorly, the same group demonstrated that different preparations of fungal laccases, such as those from Funalia trogii (Berk.) Bondartsev \& Singer, Pleurotus flabellatus (Berk \& Br) Sacc, Pleurotus eryngii (DC.) Quél., Pleurotus lampas (Berk.) Sacc. and Trametes spp., applied to skim milk yoghurt not only cross-linked milk proteins in a dose dependent manner but were also nearly unaffected by ions of the milk. Furthermore, Pleurotus eryngii laccase and anillin as mediator enhanced all rheological parameters of yogurt (Struch et al., 2016).

Mokoonlall, Pfannstiel, Struch, Berger, and Hinrichs (2016) searched for the effect of a laccase post-treatment on the microstructure and rheological properties of fresh cheese and yoghurt, a study that was subsequently complemented by Mokoonlall, Sykora, et al. (2016) that investigated the use of laccase and laccase-mediator systems as a post-processing step in stirred yoghurt at pilot scale. Both studies did not achieve the expected results. In the first study the radical directed reactivity of the laccase may have led to milk protein degradation and in the second one the laccase-mediator system caused simultaneous protein cross-linking and fragmentation with an overall negative impact on the fermented milk gel structure and sensory perception. The cross-linking activity of a purified recombinant laccase Ery4 (purified from Pleurotus eryngii and expressed in Saccharomyces cerevisiae (Desm. Meyen), with chlorogenic acid as mediator, was firstly evaluated in milk and then used in curd manufacture with improvements in both yield and antioxidant properties (Loi, Quintieri, Fanelli, Caputo, \& Mulè, 2018). Finally, Hou, Yang, Fu, Wang, and Xiao (2016) developed a new method for producing tofu with a double-network modified by laccase which resulted in an improvement in texture with great potential of being incorporated by the tofu industry.

\subsection{Laccases in the synthesis of new compounds with antioxidant and antimicrobial properties}

Laccases have the capability of polymerizing phenolics to produce derivatives with increasing antioxidant properties (Andre \& Robert, 2015a, 2015b; Chong, Guojian, Xiaojian, \& Jianna, 2019; Chong, Jianna, Zhaoxin, \& Fengxia, 2017; Liu et al., 2018; Longfang, Yongxia, Taotao, Xudong, \& Ying, 2018; Reano, Pion, Domenek, Ducrot, \& Allais, 
2016; Thakur, Kalia, Pathania, Sharma, \& Schauer, 2016). A good and interesting example on this respect is a study conducted by Adelakun et al. (2012a), two dimeric products $(\beta-5$ and $\beta-\beta)$ were obtained in a ferulic acid modification reaction catalyzed by the Trametes pubescens laccase. The $\beta-5$ dimer (Fig. 3) showed amplified antioxidant activity compared to the ferulic acid substrate, as measured by the DPPH (2, 2-diphenyl-1-picrylhydrazyl) and ABTS methods. This behavior is most likely related to the increase in electron donor groups and the formation of a carboxylic acid group with an adjacent unsaturated $\mathrm{C}-\mathrm{C}$ double bond, which provides local additional attack points for the radicals.

A further example is the use of the laccase from Trametes pubescens (Schumach.) Pilát in the oxidation of 2,6-dimethoxyphenol for the production of compounds with higher antioxidant capacity than the starting substrate (Adelakun et al., 2012b). The main product was a dimer $(m / z$ 305.0672), characterized as a symmetrical C — C linked 3,3', 5,5'-tetramethoxy biphenyl-4,4'-diol (Fig. 4). The dimer showed higher antioxidant capacity than the substrate.

Campos et al. (2016) have also used a laccase to synthesize 4, 4 '-biphenyldiamine, utilizing $p$-chloroaniline as substrate by means of a coupling reaction. The antifungal and antioxidant activity against Botryotinia fuckeliana (de Bary) Whetzel [Botrytis cinerea] was evaluated. The synthesized compound exhibited low antifungal activity but, compensating this, the antioxidant ability was increased by the dimerization of $p$-chloroaniline.

These new molecules are of great interest for biotechnological applications and can be used as antioxidant additives for packaging polymers. The purpose is to prevent oxidative deterioration of packaged food products, what generally results in great economic and health benefits. In view of these aspects, laccase-catalyzed grafting of ferulic acid was carried out on the lignin component of coconut fibers to increase microbial resistance and moisture (Thakur et al., 2016). The results showed that rich coconut fibers can be successfully modified by laccases for the development of antibacterial materials, with a concomitant improvement of their thermal and hydrophobic properties. This, in turn, is likely to increase the potential application in the food industry as packaging material. For example, Andre and Robert (2015a, 2015b) have patented the use of a laccase to modify a paper pulp useful for food packaging. In the technique, the laccase is added to the paper pulp in order to cause polymerization of at least some of its lignin. This generates a treated pulp that reduces the migration of mineral oils from paper food packaging to the packaged foods.

Reano et al. (2016) described the synthesis, properties and characteristics of novel bio-based oligomers with bisguaiacol-type moieties. These oligomers were successfully synthesized from ferulic acid based bisphenols by an environmentally friendly biocatalytic procedure utilizing the laccase from Trametes versicolor. It was proposed that these new oligomers could be used as promising sustainable antioxidant/antiradical additives for polymers.

The increasing demand for antioxidant compounds for application in food industry, has boosted the investigations of new production methods for the obtainment of derivatives with improved biological activities. One of the most promising methods is the application of laccase in antioxidant synthesis. An example of this trend is the oxidative oligomerization of esculin by laccase from Trametes versicolor in the presence of ethanol as co-solvent for food applications (Muñiz-Mouro et al., 2017). The products formed exhibited excellent antioxidant properties with great potential of being used as pharmaceutical or nutraceutical (Fig. 5).

Furthermore, it was found that the application of laccase in the enzymatic synthesis of hydroxycinnamoyl-peptide derivatives using ferulic acid and carnosine allowed the synthesis of two new derivatives (Aljawish, Chevalot, Madad, Paris, \& Muniglia, 2016). Both synthesized compounds improved the anti-proliferative activity of ferulic acid and the anti-proliferative and the antioxidant activities of carnosine. These
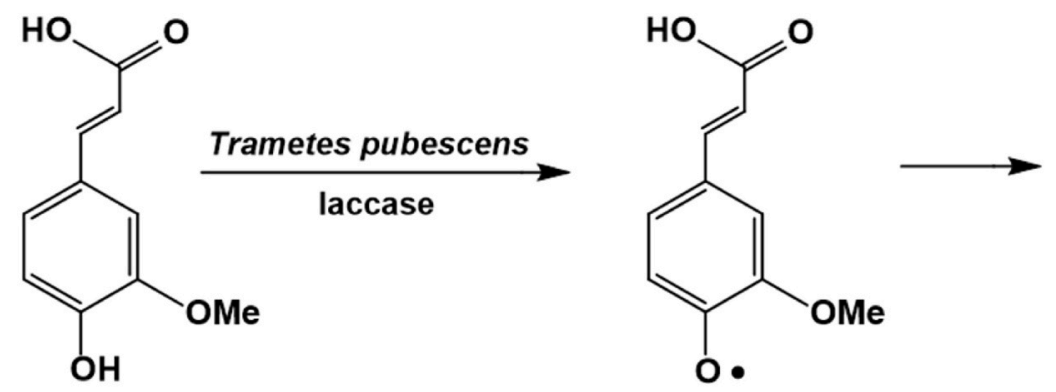

Ferulic acid

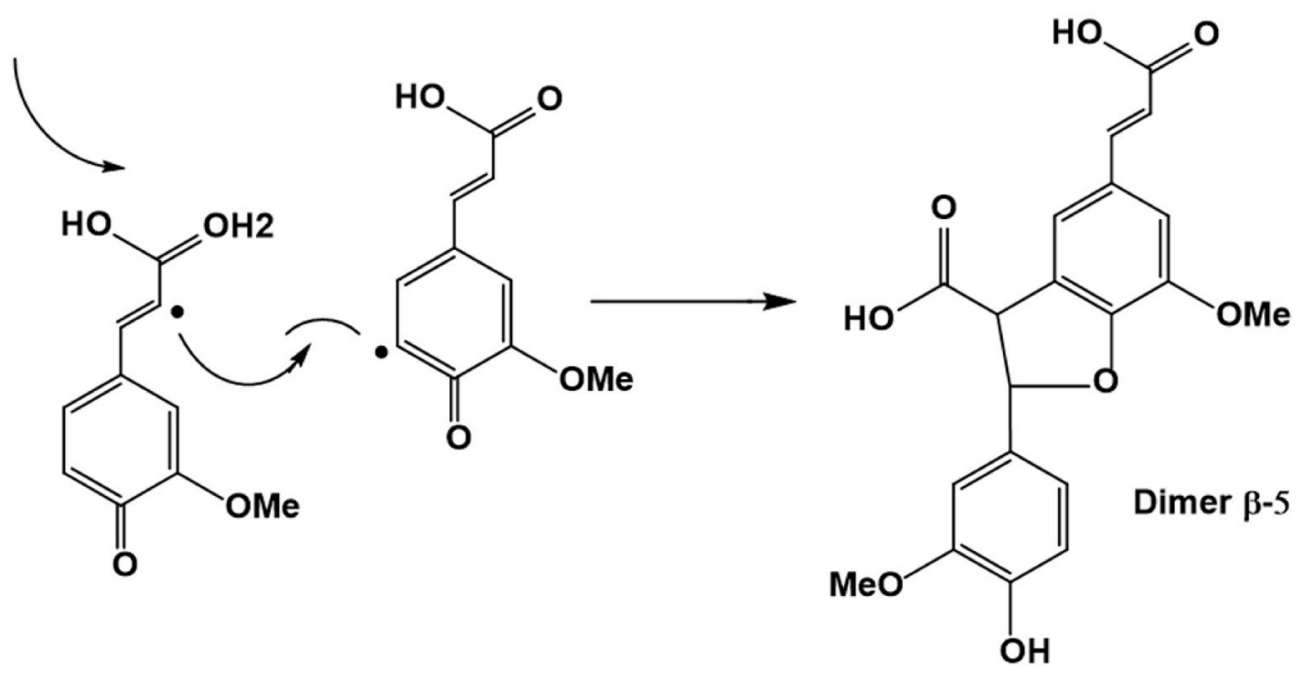

Fig. 3. Laccase-catalyzed oxidation of ferulic acid to produce $\beta-5$ dimer (modified from Adelakun et al., 2012a. 
<smiles>COc1cccc(OC)c1OCC(C)(C)C(C)(C)C</smiles>

\section{2,6-Dimethoxyphenol}<smiles>COc1cc(-c2cc(OC)c(OCC(=O)O)c(OC)c2)cc(OC)c1O</smiles>

Fig. 4. Formation of the dimer of 2,6-dimethoxyphenol from 2,6 dimethoxyphenol by laccase from Trametes pubescens, modified from Adelakun et al., $2012 \mathrm{~b}$.

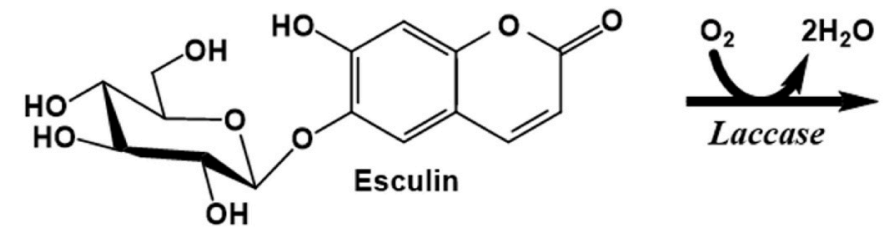

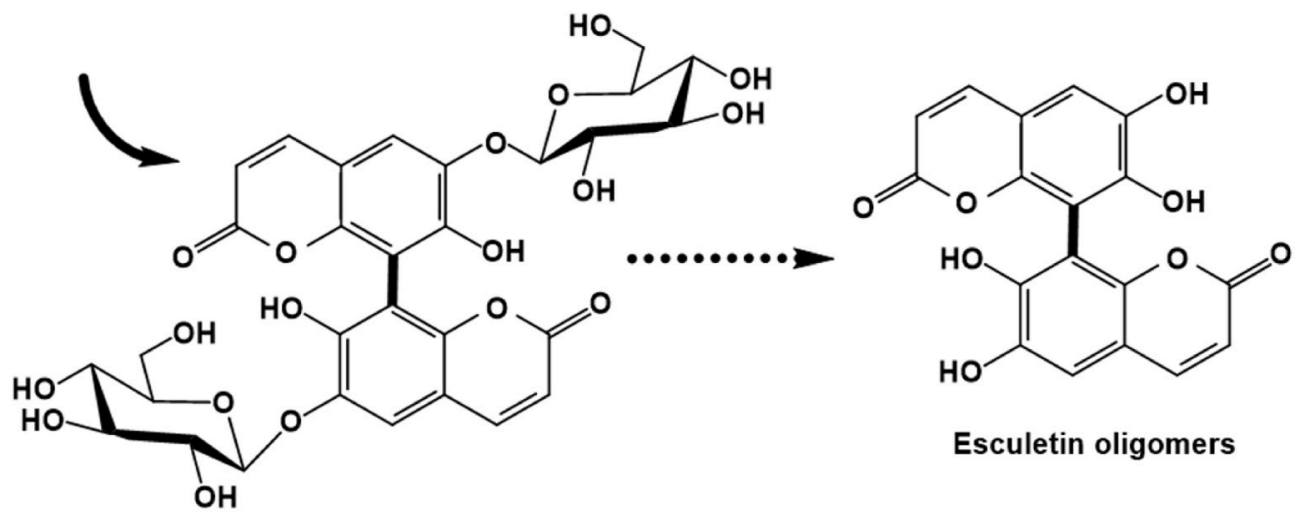

\section{Esculin oligomers}

Fig. 5. Products of oligomerization of esculin by Trametes versicolor laccase, modified from Muñiz-Mouro et al. (2017).

results suggest that coupling of the oxidized phenols with carnosine utilizing laccase is a promising process for enhancing the carnosine properties.

Nemadziva, Roes-Hill, Koorbanally, and Kudanga (2018) reported for the first time the use of a small laccase, SLAC, a two-domain bacterial laccase native to Streptomyces coelicolor Müller A3(2), in the synthesis of a $\beta-\beta$ caffeic acid dimer, phellinsin $\mathrm{A}$. The dimer exhibited enhanced antioxidant and solubility properties compared to the parent caffeic acid. In the same line, Muñiz-Mouro et al. (2017) carried out a T. versicolor laccase-mediated oxidative oligomerization of rutin. The high molecular weight oligomer fractions had improved properties when compared to the lower weight oligomers.

\subsection{Laccases in the transformation of food polymers by crosslinking}

Crosslinking can occur via aromatic groups present in proteins or carbohydrates or through certain amino acid moieties present in proteins. Crosslinking can be a result of direct enzymatic catalysis of crosslink formation, or occur indirectly by enzymatic production of a crosslinking agent, such as $\mathrm{H}_{2} \mathrm{O}_{2}$ or lipid-derived radicals, which in turn 
are able to oxidize reactive structures with subsequent crosslink formation. Proteins have several reactive groups for crosslinking enzymes, such as glutamine, lysine, tyrosine and cysteine residues. The reactions obtained are dependent on the type of enzyme used, the accessibility of the target reactive groups in the biopolymer and on process conditions used. In the case of carbohydrates, only feruloylated polysaccharides such as arabinoxylans and pectins can form crosslinks. Potential enzymes for crosslinking are transglutaminases and oxidases such as tyrosinases, glucose oxidases and laccases, among others (Isaschar-Ovdat \& Fishman, 2018).

A laccase from Funalia trogii was successfully used in the crosslinking of sugar beet pectin to an edible gel (Khalighi, Berger, \& Ersoy, 2020b). Formation of 8-5' dehydrodimers of ferulic acids were responsible for the formation of the cross-linked sugar beet pectin gels (Fig. 6). The new materials are firm, heat resistant gels, formed at room temperature and could befind application in pharmaceutical and other industries. They also represent an ethical alternative for manufacturing vegan, halal, and kosher food.

A laccase from Trametes versicolor was recently used to prepare rice glutelin/sugar beet pectin composite gels (Wang, Yang, Li-Sha, \& Chen, 2021). The rheological and textural properties in addition to the water holding capacity of the composite gels can be improved by $200 \mathrm{mM}$ calcium ions. The laccase from Myceliophthora thermophila (Apinis) van Oorschot was used to modify the citrus pectin with ferulic acid-oxidation products (Karaki et al., 2017). Spectral data suggest that covalent bonds between the pectin carboxyl groups and ferulic acid-oxidation products were established. Probably the modified pectin contains 5 times more phenolic compounds than the native pectin, and presents a significant improvement in its antioxidant properties.

Arabinoxylans from wheat bran were cross-linked by laccases from Funalia trogii (Berk.) Bondartsev \& Singer and P. pulmonarius (Khalighi, Berger, \& Ersoy, 2020a). Covalent crosslinking was proven by 8-O-4 dimers of ferulic acids as well as clusters of diferulic acids. Using laccases as an oxidant provided gels with a solid and stable texture, comparable in firmness to traditional gelatin gels.

An effective method to functionalize chitosan with 4-hexyloxyphenol under homogeneous reaction conditions was developed using laccase as the catalyst (Liu et al., 2018). This new composite exhibited a heterogeneous surface and thermal stability in addition to double functionalities (i.e., antioxidant and hydrophobic properties), allowing its use as food packaging material or coating agent.
A method that uses laccases from Bacillus vallismortis, Bacillus dysgallis fmb-103 and Bacillus thuringiensis Berliner fmb-103 to prepare chitosan derivatives with antioxidant and antibacterial actions for food preservation has been patented (Chong, Guojian, Xiaojian, \& Jianna, 2018). This invention uses recombinant bacterial laccase as catalyst to promote the covalent grafting of various phenolic compounds with antioxidant and antibacterial properties to chitosan molecules. A new method using laccase was patented for preparing a double crosslinked chitosan film with potential application in food packaging (Qingjie et al., 2019). The obtained film has characteristics as green color, low toxicity and high food safety.

A recombinant bacterial laccase from Bacillus vallismortis fmb-103 (fmb-rL103) was used for preparing a ferulic grafted chitosan (Yang et al., 2018). Both antioxidant and antibacterial properties against E. coli, S. aureus, B. subtilis, and M. guilliermondii were improved. This new material was applied to mango preservation as a coating, improving the sensory qualities of mango Mangifera indica L.

Longfang et al. (2018) developed a method for preparing a phenolic acid grafted chitooligosaccharide using laccase. This new chitooligosaccharide structure containing waterborne polyurethane showed good heat resistance stability and excellent mechanical properties and can, thus, be applied as food film.

A thermostable recombinant bacterial laccase from Bacillus dysgallis was used in the obtainment of a protein/polysaccharide composite membrane (Chong et al., 2019). The composite film was prepared by mixing protein, pectin and chitosan as base material. This was followed by the addition of a plasticizer, a surfactant and a recombinant bacterial laccase as the crosslinking agent. The film that was formed had tensile strength, ductility and antibacterial properties and could be utilized in food packaging materials. Likewise, Quanzhong (2017) developed a composite packing paper coating liquid from a laccase-grafted modified chitosan in association with palm emulsion. Analysis of the coating liquid showed antibacterial properties making it suitable for coating food packaging paper.

A method for preparing a whey protein film by using thermostable recombinant laccase from Bacillus vallismortis Roberts has also been patented (Chong et al., 2017). The material can be used as a plasticizer, and the whey protein film which is reconstituted by using laccase as a crosslinking agent is green and edible, with tensile strength, light transmittance, water absorption degree and plasticity.

Ning, Xiao, Jianwen, Baoyao, and Li (2016) patented a new

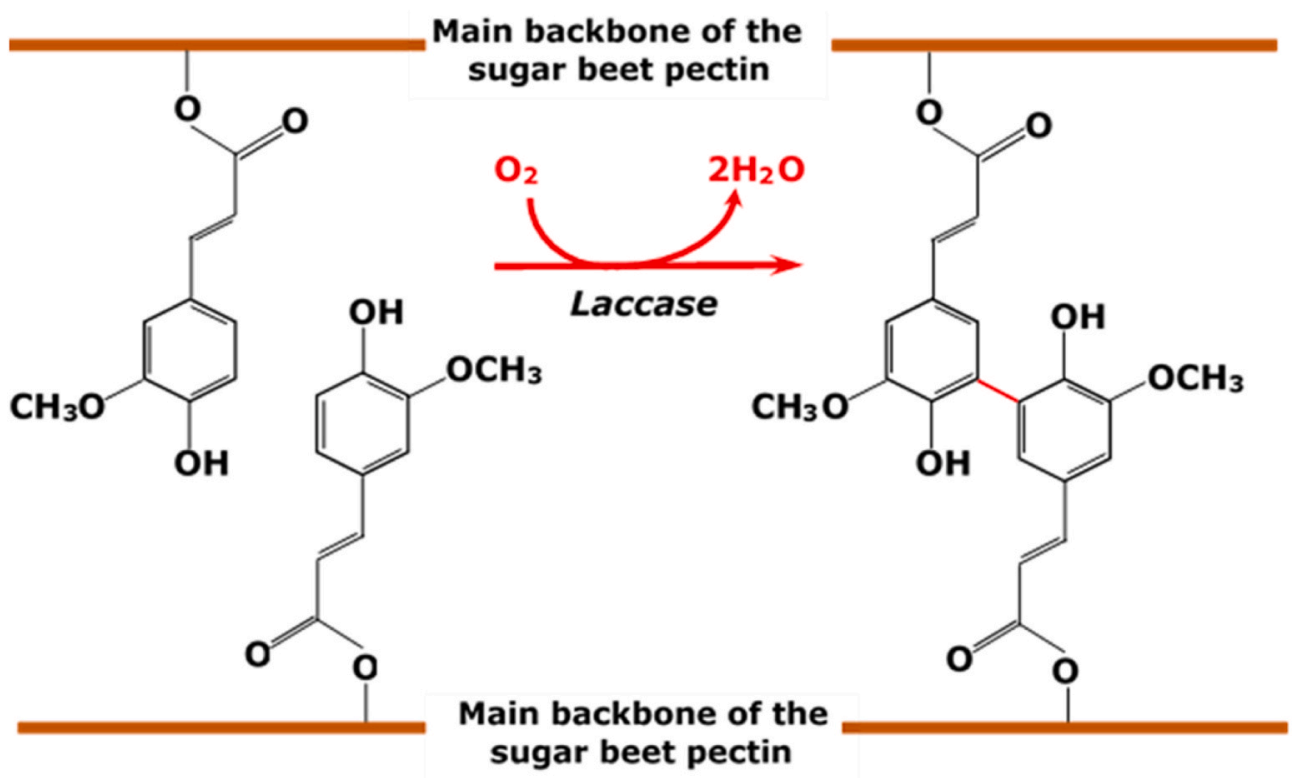

Fig. 6. Cross-linking reaction of sugar beet pectins, modified from Khalighi et al. (2020b). 
enzymatic method with laccase for preparing a functional rice bran protein using ferulic acid and rice protein to obtain a product with high antioxidant activity.

A technique that utilizes laccase to cross-link $\alpha$-lactalbumin was patented. The purpose was to improve its functional properties as well as its oxidation resistance, gelability, water holding capacity and emulsification stability. The modified $\alpha$-lactalbumin polymer had enhanced antioxidant activity when compared to the parent $\alpha$-lactalbumin (Kun, Ling, Tianqi, Xi, \& Xindi, 2019; Zhanmei, Liang, Chunyan, \& Xiangying, 2018). More recently, a commercial laccase from Aspergillus sp. was used in combination with ultrasound in a crosslinking treatment of $\alpha$-lactalbumin ( $\alpha$-LA) for the obtainment of stabilized emulsions. The $\alpha$-LA has good emulsifying and foaming properties, but poor gelation activity. The combined ultrasound pretreatment and laccase crosslinking had a significant influence on the functional, structural and rheological properties of the $\alpha$-LA emulsion gel (Qayum et al., 2021).

The crosslinking of casein by using laccase and ferulic acid improved protein the emulsifying properties of derivative (Sato et al., 2015). Laccase has also been used in the functionalization of polysaccharides such as gum arabic with oxidation products of phenols (Vuillemin et al., 2020). The laccase-catalyzed chitosan-gallic acid derivative showed improvement in the antibacterial activity against Escherichia coli and Staphylococcus aureus (Li, Guan, Zhu, Wu, \& Sun, 2019). Additionally, laccase catalyzed covalent crosslinking of the feruloyl groups to form diferulic acids in a solubilized feruloylated glucuronoarabinoxylan extracted from corn bran resulted in the formation of firm hydrogels (Munk et al., 2020). This technique appears to be a promising way to produce new functional derivatives with improved properties that are expected to broaden the scope of polysaccharides. Through laccase it is possible to modify compounds present in food, allowing the production of healthier and economically viable products. For instance, laccases have been successfully applied to improve sensorial (Hou et al., 2016; Lettera et al., 2016) and rheological (Struch et al., 2016) properties of several food products, producing (Schirmann, Dekker, Borsato, \& Barbosa-Dekker, 2018) or increasing (Nemadziva et al., 2018) bioactive compounds in foodstuffs, besides composing food packing or coating material (Reano et al., 2016).

Chan, Zeeb, McClements, and Weiss (2017) evaluated the impact of a crosslinking enzyme laccase (T. versicolor) on the color stability of structured oil-in-water emulsions containg a lipophilic model colorant (Nile red). They found that laccase can be used in emulsions to improve physical stability in front of environmental stress, such as changes in temperature, ionic strength or $\mathrm{pH}$. Its use is limited, however, because it promotes color fading. More recently, Chen et al. (2018) aimed at improving the stability of the emulsifying action of sugar beet pectin by covalent coupling of proteins (bovine serum albumin) to the polysaccharide through a Maillard reaction/laccase catalysis. The authors claim to have obtained excellent results because the covalent conjugates exhibited an improved emulsion stability under a variety of extreme conditions, including thermal and freeze-thawing treatment, salt exposure and low $\mathrm{pH}$ value.

Yanxiang and Di (2018) described in a patent a method for preparing a protein-polyphenol-polysaccharide covalent complex in which a laccase is used in the process. The compound that was formed exhibited good antioxidant capacity and thermal stability with potential application in food industries as an emulsifier to prepare $\beta$-carotene emulsions.

\subsection{Further potential applications of laccases in food processing}

Potential applications of laccases for modifying or improving food quality are illustrated by Fig. 7. Two of the topics in Fig. 7, synthesis of novel bioactive compounds and transformation of food polymers by crosslinkg, were already discussed in subsections 4.5 and 4.6, respectively. The remaining six will be briefly outlined below. The purposes they are intended to serve are multivariate, a fact that certainly emphasizes the potentialities of the laccases as useful tools in food processing and development.

1) Diminishing flavor and aroma deterioration. Contaminating microorganisms such as Actinomycetes, Alicyclobacillus, and Chlostridium can generate off-flavors in different juices, including apple juice and orange juice (Huang, Yuan, Guo, Gekas, \& Yue, 2015). Spoiled fruit

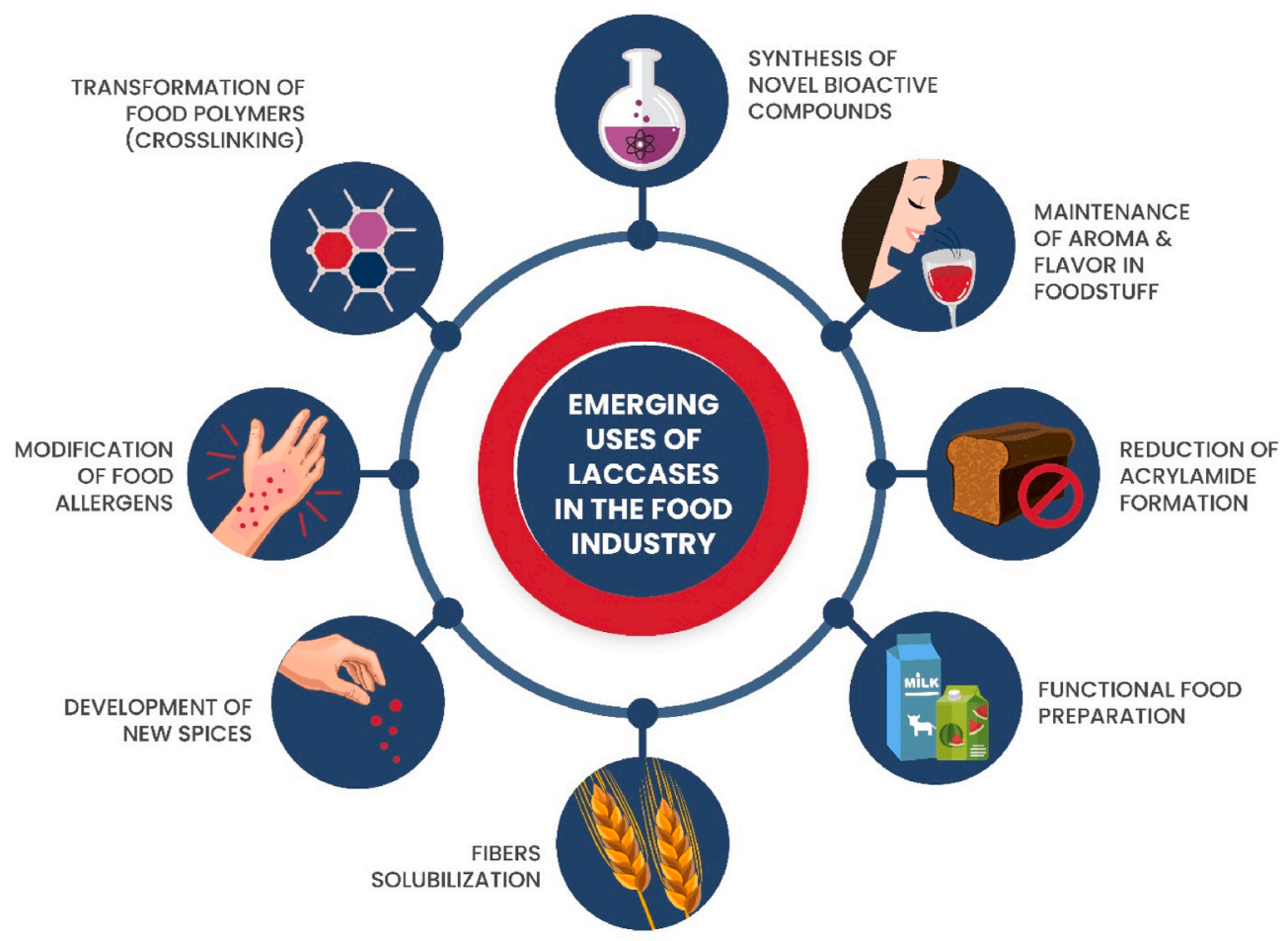

Fig. 7. Newest applications of laccases in food processing. 
juices exude an undesirable off-flavor or off-odor, described as medical, hammy, or smoky. The off-flavor or off-odor is mainly imputed to the chemical compounds guaiacol, 2,6-dibromophenol, and 2,6-bichlorophenol. An immobilized Trametes hirsuta laccase has already been applied for the selective elimination of off-flavor substances in apple juice caused by microbial contamination (Schroeder et al., 2008). The evaluation using gas chromatography mass spectrometry showed that enzymatic treatment could reduce the amount of guaiacol and 2,6-dibromophenol in apple juice significantly by 99 and $52 \%$, respectively. At least in principle, laccases can be useful in diminishing flavor and aroma deterioration of other juices, such as orange juice, and foods. In the same way flavor and aroma of carotenoids can deteriorate by a series of factors related to light exposure, heating or changes over time in foods and beverages. Takeshi, Maiko, and Michiyuki (2016) have patented an effective and highly safe method that uses laccase for suppressing the loss of flavor and aroma in foods. Finally, a recombinant laccase from Pediococcus acidilactici CECT 5930 was efficient in degrading biogenic amines such as tyramine, which are generated from fermentation of raw foods. Removal if this toxic compound and improved the organoleptic properties of food (Callejón, Sendra, Ferrer, \& Pardo, 2017). Tyramine and other biogenic amines are produced by bacterial decarboxylation of corresponding amino acids in foods and when present in high amounts can cause nausea, diarrhea, vomit, and hypertension, among other problems (Doeun, Davaalseren, \& Chung, 2017).

2) Reducing the formation of neurotoxic acrylamide. Heating of food induces chemical reactions that lead to the formation of heat-induced toxic substances, the so-called thermal process contaminants. Acrylamide is one of these compounds that has received much attention over the recent years (Rifai \& Saleh, 2020). Acrylamide is formed from the reaction of reducing sugars (e.g., glucose or fructose) with the amino acid asparagine via the Maillard reaction, which occurs during heat processing of foods, such as potato and cereal products, to temperatures above $120^{\circ} \mathrm{C}$ (Lineback, Coughlin, \& Stadler, 2012). Enzymatic methods have been considered to mitigate the formation of acrylamide, being those employing asparaginase the most extensively studied (Rottmann, Hauke, Krings, \& Berger, 2021). The formation of acrylamide during heat treatment in the production of a food can also be reduced by treating the raw material with laccase (or a peroxidase) before the heat treatment. The enzyme is capable of acting on asparagine or glutamine (optionally substituted) (Budolfsen, 2015).

3) Solubilizing insoluble dietary fibers. Soluble dietary fibers are functionally and nutritionally more important than insoluble dietary fibers. Consequently, much attention has been focused on the solubilization of dietary fibers through diverse techniques, including mechanical degradation, extrusion cooking, thermal processes, chemical treatment, enzymatic methods, and microbiological fermentation (Ain et al., 2019). A deoiled cumin dietary fiber was modified by high hydrostatic pressure-enzyme (laccase and cellulose) treatment. Deoiled cumin dietary fiber consists in $12.26 \%$ soluble and $71.92 \%$ insoluble dietary fiber. After treatment, the content of the soluble dietary fiber was increased to $30.37 \%$ and te cumin dietary fiber presented, as a whole, an improved capacity of absorbing water, fats, carbohydrates, and bile acids and exhibited antioxidant capacity (Ma \& Mu, 2016). A method was patented (Taihua, Xingli, et al., 2015) which uses laccase and cellulase to modify the cumin dietary fiber under ultra-high pressure to degrade water-insoluble lignin. The procedure converts this otherwise insoluble dietary fiber into a water-soluble dietary fiber. It has been claimed that the patented method is highly effective and that it can be easily expanded on industrial scale.

4) Modifying food allergens. Food allergy has become a serious health concern, especially in developed countries, and the financial and social implications related to these conditions are increasing worldwide (Renz et al., 2018). Many of the food allergens are stable proteins that are very resistant to digestion by gastrointestinal enzymes or can be digested into high molecular weight peptide fragments which retain the IgE binding and T-cell stimulating capacities. Crosslinking of proteins has been shown to affect their allergenic properties. Numerous examples were found in the literature, most of them using laccase from Trametes sp. A laccase from Trametes hirsuta with caffeic acid as mediator was more efficient than tyrosinase from Trichoderma reesei, tyrosinase from Agaricus bisporus and transglutaminase from Streptoverticillium mobaraense in mitigating the IgE binding and allergenicity of the bovine $\beta$-casein (Stanic et al., 2010). The T. hirsuta laccase was also used for crosslinking peanut proteins aiming at producing changes in the biological and immunological properties with consequent changes in the sensitizing potential of allergens. The results have revealed a reduction of the immune response to peanut proteins in vivo. In parallel, the laccase treatment depleted the peanut extract of polyphenolic compounds, leaving mostly procyanidin dimer B-type and isorhamnetin derivatives (Mihajlovic et al., 2016). A laccase from Trametes versicolor was used for crosslinking of $\beta$-lactoglobulin, using sour cherry phenolics as mediators. The allergenicity of cross-linked protein decreased in all nine cow's milk-allergic patients, while digestibility of the remaining monomeric $\beta$-lactoglobulin in simulated conditions of the gastrointestinal tract increased. (Tantoush et al., 2011). A laccase from Coriolus versicolor was used for crosslinking of Paralichthys olivaceus parvalbumin using propyl gallate as mediator. Western blotting and indirect ELISA analysis revealed the decrease in IgG binding capacity of parvalbumin, corresponding to the structural changes. In vitro digestion showed that after laccase treatment, parvalbumin was more resistant to gastrointestinal digestion (Lv et al., 2019).

5) New spices. Spices have been used since ancient times. Spices are employed mainly as flavoring and coloring agents, but their role in food safety and preservation have also been studied in vitro and in vivo (Gottardi, Bukvicki, Prasad, \& Tyagi, 2016). Spices and herbs such as clove, rosemary, sage, oregano, and cinnamon are excellent sources of antioxidants with their high content of phenolic compounds (Alan Jiang, 2019). Certainly, laccases can be used for improving the qualities of these spices and represent represents a wide field of application for laccases. A new food spice was patented and in one of the stages of preparing it a laccase was used. The invention warrants a smooth taste to the low cost product (Jinfang \& Yongxing, 2019).

6) Generation of functional foods. The transformations caused by the actions of laccases in the constituent molecules of different foods show that these enzymes alter the properties and functionality of various foods. Several examples were already described in the preceding topics and two more will be described here. Ginkgo biloba ( $G$. biloba) leaf extracts have been used for medical purposes due to the presence of various bioactive compounds. However, it contains ginkgolic acid, which is considered to be a toxic, allergenic, and mutagenic substance, limiting thus, the practical applications of G. biloba in the industry (Wang, Zhu, et al., 2018). A Trametes versicolor laccase immobilized on core/shell $\mathrm{Fe}_{3} \mathrm{O}_{4}$ /nylon composite nanoparticles using a novel coaxial electrospraying process efficiently degraded theginkgolic acids from the G. biloba leaf extract (Chen et al., 2021), eliminating, thus, the main causes for the toxic properties of the plant preparations. Another application refers to macromolecule crosslinking that can be promoted by oxidases in general (laccases, peroxidases and tyrosinase). Crosslinking has been widely used in the construction of food colloids, e.g., to form and stabilize emulsions, nanoparticles, and gels. A recent review delineates the mechanisms by which food molecules are cross-linked by oxidases and compares the applications of the diverse oxidases in food colloidal systems ( Li et al., 2020). The effects of a laccase from Trametes versicolor on the rheological properties and microstructure of fermented milk products, namely, yoghurt and fresh cheese, was 
evaluated. The enzymatic crosslinking of tyrosine residues in milk proteins is expected to lead to improved structural characteristics of milk gels. (Mokoonlall, Pfannstiel, et al., 2016).

\section{Bottlenecks and perspectives}

Notwithstanding all the advantages of using the laccases as described in the preceding sections, a large industrial application of these enzymes in food processing is yet often hampered by several factors (Fig. 8). The text that follows, evidently, is limited by the information that is currently available in the pertinent literature. Current industrial developments are not always announced in sufficient detail so that critical analysis often becomes a very difficult task.

The cost is one of them in spite of the fact that there are currently six major laccase suppliers all over the world, namely Novozymes, DuPont, Amano Enzyme, Yiduoli, Sunson and Denykem (Zerva et al., 2019). It must be stressed, however, that most of these commercial laccases are not recommended for food purposes, but rather for environmental and bioenergy areas. Numerous strategies have already been devised to reduce the production costs of laccases, including the isolation of new natural hypersecretory strains (Iark et al., 2019; Songulashvili et al., 2015), the heterologous expression of laccase genes (Tulek et al., 2020) and the optimization of enzyme production (Tisma, Znidarsic-Plazi, Vasic-Racki, \& Zelic, 2012; Wang, Hu, Guo, \& Liu, 2016). In spite of these efforts, the production of laccases still remains quite expensive (Antošová \& Sychrová, 2016; Yang et al., 2017). Osma, Toca-Herrera, and Rodríguez-Couto (2011) compared the cost of production of laccase by the white-rot fungus Trametes pubescens using different media under both submerged and solid-state cultivation. They found that in solid state cultivation under optimized conditions, it was possible to produce laccase at laboratory scale, with a final price of 0.04 cent $€$ per unit. More recently, laccase from the white-rot fungus Ganoderma lucidum was produced in $30 \mathrm{~L}$ bioreactors using the hemicellulose-rich liquor as carbon source (Lú-Chau et al., 2018). Economic analysis of the latter process resulted in a $€ 1.08 \mathrm{kU}^{-1}(0.01$ cent $€$ per unit). The same cost was computed for the production of laccase in submerged cultures of Cerrena unicolor C-139 in a $120 \mathrm{~L}$ stirred bioreactor using wheat bran as substrate (Songulashvili et al., 2015).

Cost reduction can be expected upon scaling up enzyme production. In this respect the commercial production of laccases still remains somewhat behind the stage already reached with several other enzymes, such as amylases and proteases. The strategies that have been proposed for improving the large scale production of laccases are generally based on external factors. It is largely known that the laccase production is affected by temperature, medium composition, $\mathrm{pH}$, aeration and agitation (Wang et al., 2016; Debnath \& Saha, 2020). Generally, fungi are cultivated in stirred-tank bioreactors, air-lift bioreactors and bubble column for submerged fermentation (Wang, Guo, \& Liu, 2013) while tray biorectors and packed bed biorectors are commonly used for solid state fermentation (Debnat \& Saha, 2020). Effective scale up the laccase production, evidently, also implies in give full consideration to the reactor design and process parameters. Shortcommings may arise, for example, by an unwanted increase in the external mass transfer resistance. It has been proposed that the external mass transfer resistance in the immobilized reactor could be reduced by increasing the velocity of the bulk solution and by improving the design of the impeller geometry, thus facilitating the overall diffusion process (Fogler, 2005).

An efficient production enzymes at bioreactor scale is frequently hampered by heterogenic morphological growth of filamentous fungi which affects the rheology of the fermentation broth and the performance of the bioreactor (Rola et al., 2013). Changes in the broth rheology affect the mass, momentum and heat transfer within the bioreactor (Charles, 1985). Moreover, it is important to adjust the inoculation during the cultivation, since fungal physiological properties such as, the age and size of the mycelial inoculum, can determine the development of fungal pellets (Rola et al., 2013).

Dwivedi, Vivekanand, Pareek, and Singh (2010) have proposed an approach to scale up the production of a xylanase-laccase mixture in an intermittent rotating drum bioreactor. The yields of xylanase and laccase were higher than those observed for other solid state bioreactors, what recommends the utilization of an intermittent rotating drum bioreactor system for scaling up the production level. Wang, Ma, Guo, Zhuang, and Liu (2013) reported the enhancement of laccase production by ultrasonic treatment, which causes improved mass transfer of nutrients and product. Therefore, sonobioreactors could be used for large scale and highly-efficient production of laccase.

Another approach to improve laccase production is the supplementation of culture medium with an appropriate inducer such as 2,5-xylidine, veratryl alcohol or guaiacol. In 200-L airlift bioreactor cultures of $T$. versicolor with addition of vanillic acid, the transcript level of $l c c$ at day 7 was 2.62-fold higher than that in flasks with vanillic acid due to the good mass transfer and oxygen supply in the bioreactor system.

Two other problems for the industrial use of laccases are the lack of long-term operational stability and the difficult recovery and re-use.

\section{Top bottlenecks hampering laccases wider application in food industry.}

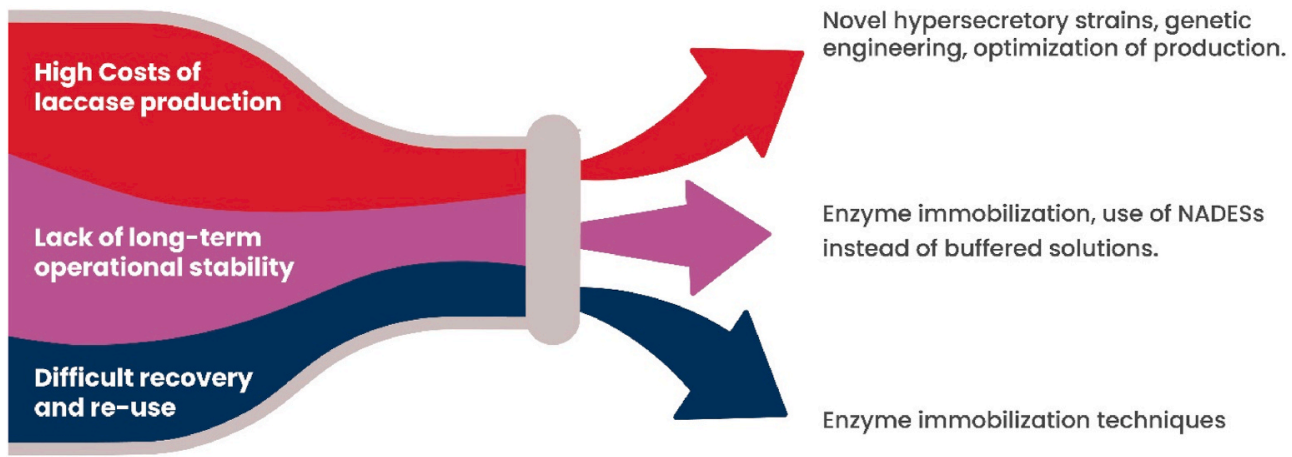

Fig. 8. Top bottlenecks hampering laccases application in food industry and the corresponding strategies to overcome them. 
These drawbacks can generally be overcome by enzyme immobilization (Fig. 8). In this respect, the immobilization on supports provides a series of catalytic advantages compared with the free enzyme, such as convenient procedures for the separation of medium, increase in the thermal mechanical resistance, improvement of the catalytic efficiency, and decrease in the limitation of substrate and product diffusion. Some immobilization protocols have allowed one-step immobilization and purification by a careful control of the support and/or immobilization conditions (dos Santos et al., 2015). Recent reviews have adressed the trends with reference to support materials for laccase immobilization (Daronch, Kelbert, Pereira, Araújo, \& de Oliveira, 2020) as well as the immobilization approaches in food processing (Taheri-Kafrani et al., 2020; Zhou, Zhang, \& Cai, 2021).

Many authors have emphasized that the success of the immobilization process consists not only in improving the enzymatic activity and the life time, but also in allowing re-usability of the enzyme (Verrastro et al., 2016). The latter affords higher product purity and lower operational costs (Lettera et al., 2016). In this context, the application of immobilized laccases instead of free laccases to juice clarification (Bezerra et al., 2015; Lettera et al., 2016; Narnoliya et al., 2019), for example, appears as a great opportunity of reducing operational costs.

An alternative procedure for improving the stability of laccases is using natural deep eutectic solvents (NADESs) instead of buffered solutions. Deep eutectic solvents have emerged as alternative non-toxic solvents for biotechnological applications, due to their biocompatibility with enzymes (Olivares et al., 2018; Sheldon, 2016; Xu, Zheng, Zong, Li, \& Lou, 2017). Recently, this method was used to alter the activity and inhibit thermal inactivation of laccase from $T$. versicolor. In this experiment, the authors used an aqueous 25 wt $\%$ betaine-xylitol based natural deep eutectic solvent at $70{ }^{\circ} \mathrm{C}$ for $15 \mathrm{~min}$. This remarkable enhancement of thermostability of the laccase could unlock a range of potential industrial applications for laccases, for example, in smart-enzyme multi-layer plastics for food packaging (Delorme, Andanson, \& Verney, 2020).

The use of laccases for developing biosensors for food analyses seems to be a promising field. There are already several studies describing applications of laccase in biosensors for quantifying phenolic compounds in beverages (Medina-Plaza et al., 2016; Rodríguez-Delgado et al., 2015; Verrastro et al., 2016; Zrinski et al., 2020). More specifically, immobilized laccases have been used for the detection of catechol (Caballero et al., 2018; Mei et al., 2015; Nazari, Kashanian, Maleki, \& Shahabadi, 2019), catechin (Aguila et al., 2015), 2,6-dimethoxyphenol (Patel et al., 2018), resorcinol (Lepore \& Portaccio, 2017), bisphenol A (Lou et al., 2019), general polyphenols (Cano-Raya, Dencheva, Braz, Malfois, \& Denche, 2020; Mohtar et al., 2019; Nazari et al., 2019), and drug derivatives (Jabbari et al., 2017).

\section{Conclusion}

With respect to the applications of laccases in the food industry, there is undoutbly a lot of research activity under way suggesting that at some point in the near future the sector could experience a kind of revolution, with a sudden expansion in the number of meaningful and valuable applications. Especially promising areas are, in our view, the synthesis of new compounds with functional properties, such as antioxidant and antimicrobial activities, and the crosslinking of polymers, such as proteins and polysaccharides. On the other hand, it should not be regarded as a surprise if the biosensor sector brings to light novel and efficient techniques for analytical purposes in which laccases participate as an essential component. Finally, scaling up of the production of the laccase itself and especially of the products derived from its applications will be essential for cost reduction and, consequently, for market expansion.

\section{Funding}

This work was supported by the National Council of Scientific and Technological Development (CNPq, Proc. 404898/2016-5). R.C.G. Corrêa is a research grant recipient of Cesumar Institute of Science Technology and Innovation (ICETI). C.G. Kato (Proc. 151189/2019-6), E. Backes (Proc. 304406/2019-8), R.M. Peralta, R.A. Peralta, R.F. Peralta Muniz Moreira and A. Bracht are research grant recipients from CNPq.

\section{Declaration of competing interest}

There are no interest conflicts.

\section{References}

Adelakun, O. E., Kudanga, T., Parker, A., Green, I. R., Roes-Hill, M. L., \& Burton, S. G. (2012a). Laccase catalyzed dimerization of ferulic acid amplifies antioxidant activity. Journal of Molecular Catalysis B: Enzymatic, 74(1-2), 29-35. https://doi.org/ 10.1016/j.molcatb.2011.08.010

Adelakun, O. E., Kudanga, T., Parker, A., Green, I. R., Roes-Hill, M. L., \& Burton, S. G. (2012b). Enzymatic modification of 2,6-dimethoxyphenol for the synthesis of dimers with high antioxidant capacity. Process Biochemistry, 47(12), 1926-3192. https:// doi.org/10.1016/j.procbio.2012.06.027

Agrawal, K., Chaturvedi, V., \& Verma, P. (2018). Fungal laccase discovered but yet undiscovered. Bioresource Bioprocess, 5, 4-16. https://doi.org/10.1186/s40643-0180190-Z

Aguila, S. A., Shimomoto, D., Ipinza, F., Bedolla-Valdez, Z. I., Romo-Herrera, J., Contreras, O. E., et al. (2015). A biosensor based on Coriolopsis gallica laccase immobilized on nitrogen-doped multiwalled carbon nanotubes and graphene oxide for polyphenol detection. Science and Technology of Advanced Materials, 16(5), Article 055004. https://doi.org/10.1088/1468-6996/16/5/055004

Ain, H. B. U., Saeed, F., Ahmed, A., Khan, M. A., Niaz, B., \& Tufail, T. (2019). Improving the physicochemical properties of partially enhanced soluble dietary fiber through innovative techniques: A coherent review. Journal of Food Processing and Preservation, 43. https://doi.org/10.1111/jfpp.13917. Article e13917.

Alan Jiang, T. (2019). Health benefits of culinary herbs and spices. Journal of AOAC International, 102, 395-411. https://doi.org/10.5740/jaoacint.18-0418

Aljawish, A., Chevalot, I., Madad, N., Paris, C., \& Muniglia, L. (2016). Laccase mediatedsynthesis of hydroxycinnamoyl-peptide from ferulic acid and carnosine. Journal of Biotechnology, 227, 83-93. https://doi.org/10.1016/j.jbiotec.2016.04.021

Amin, R., Khorshidi, A., Shojaei, A. F., Rezaei, S., \& Faramarzi, M. A. (2018). Immobilization of laccase on modified $\mathrm{Fe}_{3} \mathrm{O}_{4} @ \mathrm{SiO}_{2} @ \mathrm{Kit}-6$ magnetite nanoparticles for enhanced delignification of olive pomace bio-waste. International Journal of Biological Macromolecules, 114, 106-113. https://doi.org/10.1016/j. ijbiomac. 2018.03.086

Andre, N., \& Robert, M. (2015b). Patent No MX363962B. Reitered from. https://patents. google.com/patent/MX363962B/en?oq=MX363962B.

Andre, N., \& Robert, M. (2015a). Patent No EP2906749A1. Reitered from. https://patents. google.com/patent/EP2906749A1/fr?oq=EP2906749A1.

Andreus, J., Silva, E. P., \& Ferreira-Leitão, V. S. (2016). Sustainable technology supported by enzymes - prevention and valorization of agroindustrial residues. Biocatalysis and Biotransformation, 3(2), 54-56. https://doi.org/10.1080/ 10242422.2016.1260626

Antošová, Z., \& Sychrová, H. (2016). Yeast hosts for the production of recombinant laccases: A review. Molecular Biotechnology, 58(2), 93-116. https://doi.org/ 10.1007/s12033-015-9910-1

Arnaut, F., Dauvrin, T., Contreras, R., Vanneste, G., \& Viaene, J. (2006). Patent No EP1637595A1. Retrieved from https://patents.google.com/patent/EP163 7595A1/en.

Bezerra, T. M. S., Bassan, J. C., Santos, V. T. O., Ferraz, A., \& Monti, R. (2015). Covalent immobilization of laccase in green coconut fiber and use in clarification of apple juice. Process Biochemistry, 50(3), 417-423. https://doi.org/10.1016/j. procbio.2014.12.009

Budolfsen, G. (2015). Patent No DK1886582T3. Reitered from. https://patents.google. $\mathrm{com} / \mathrm{patent} / \mathrm{DK} 1886582 \mathrm{~T} 3 / \mathrm{en}$ oq=DK1886582T3.

Caballero, S. J., Guerrero, M. A., Vargas, L. Y., Ortiz, C. C., Castillo, J. J., Gutiérrez, J. A., et al. (2018). Electroanalytical determination of catechol by a biosensor based on laccase from Aspergillus oryzae immobilized on gold screen-printed electrodes. Journal of Physics: Conference Series, 1119, Article 012009d. https://doi.org/ 10.1088/1742-6596/1119/1/012009

Callejón, S., Sendra, R., Ferrer, S., \& Pardo, I. (2017). Recombinant laccase from Pediococcus acidilactici CECT 5930 with ability to degrade tyramine. PloS One, 12, Article e0186019. https://doi.org/10.1371/journal.pone.0186019. Article.

Campos, A. M., Mendoza, L., Vasquez, J., Melo, R., Salas, J., \& Cotoras, M. (2016). Lacasse catalyzed-synthesis of 4,4' biphenyldiamine from p-chloroaniline. Evaluation of antifungal and antioxidant activites. Journal of the Chilean Chemical Society, 61, 3031-3033. https://doi.org/10.4067/S0717-97072016000300004

Cano-Raya, C., Dencheva, N. V., Braz, J. F., Malfois, M., \& Denche, Z. Z. (2020). Optical biosensor for catechol determination based on laccase-immobilized anionic 
polyamide 6 microparticles. Journal of Applied Polymer Science, 137(38), Article e49131. https://doi.org/10.1002/app.49131. Article.

Chan, C. K. Y., Zeeb, B., McClements, D. J., \& Weiss, J. (2017). Impact of laccase on the colour stability of structured oil-in-water emulsions. Food Research International, 97, 223-230. https://doi.org/10.1016/j.foodres.2017.04.015

Charles, M. (1985). Fermentation scale-up: Problems and possibilities. Trends in Biotechnology, 3, 134-139. https://doi.org/10.1016/0167-7799(85)90101-5

Chauhan, P. S., Goradia, B., \& Saxena, A. (2017). Bacterial laccase: Recent update on production, properties and industrial applications. 3 Biotech, 7(5), 323-343. https:// doi.org/10.1007/s13205-017-0955-7

Chen, H., Ji, A., Qiu, S., Liu, Y., Zhu, Q., \& Yin, L. (2018). Covalent conjugation of bovine serum album and sugar beet pectin through Maillard reaction/laccase catalysis to improve the emulsifying properties. Food Hydrocolloids, 76, 173-183. https://doi. org/10.1016/j.foodhyd.2016.12.004

Chen, H.-Y., Ting, Y., Kuo, H.-C., Hsieh, C.-W., Hsu, H.-Y., Wu, C.-N., et al. (2021). Enzymatic degradation of ginkgolic acids by laccase immobilized on core/shell $\mathrm{Fe}_{3} \mathrm{O}_{4}$ /nylon composite nanoparticles using novel coaxial electrospraying process. International Journal of Biological Macromolecules, 172, 270-280. https://doi.org/ 10.1016/j.ijbiomac.2021.01.004

Chong, Z., Guojian, B., Xiaojian, Z., \& Jianna, S. (2018). Patent No CN107586800A. Reitered from. https://patents.google.com/patent/CN107586800A/zh.

Chong, Z., Guojian, B., Xiaojian, Z., \& Jianna, S. (2019). Patent No CN109111584A. Reitered from. http://www.jmrhip.com/static/patent/html/CN109111584A.html.

Chong, Z., Jianna, S., Zhaoxin, L., \& Fengxia, L. (2017). Patent No CN104672919B. Reitered from. https://patents.google.com/patent/CN104672919B/zh.

Daronch, N. A., Kelbert, M., Pereira, C. S., Araújo, P. H. H., \& de Oliveira, D. (2020). Elucidating the choice for a precise matrix for laccase immobilization: A review. Chemical Engineering Journal, 397. https://doi.org/10.1016/j.cej.2020.125506. Article 125506 .

Debnath, R., \& Saha, T. (2020). An insight into the production strategies and applications of the ligninolytic enzyme laccase from bacteria and fungi. Biocatalysis and Agricultural Biotechnology, 26. https://doi.org/10.1016/j.bcab.2020.101645. Article 101645.

Delorme, A. E., Andanson, J. M., \& Verney, V. (2020). Improving laccase thermostability with aqueous natural deep eutectic solvents. International Journal of Biological Macromolecules, 163, 919-926. https://doi.org/10.1016/j.ijbiomac.2020.07.022

Doeun, D., Davaalseren, M., \& Chung, M.-S. (2017). Biogenic amines in foods. Food Science and Biotechnology, 26, 1463-1474. https://doi.org/10.1007/s10068-0170239-3

Dwivedi, P., Vivekanand, V., Pareek, N., \& Singh, R. P. (2010). Bleaching applications and scaled-up production of xylanase-laccase mixture in a intermittent rotating drum bioreactor. Journal of Biotechnology, 150(Supplement), 75-76. https://doi.org/ 10.1016/j.jbiotec. 2010.08 .195

Fogler, H. S. (2005). Elements of chemical reaction engineering (4th ed.). Prentice Hall.

Forootanfar, H., \& Faramarzi, M. A. (2015). Insights into laccase producing organisms, fermentation states, purification strategies, and biotechnological applications. Biotechnology Progress, 31(6), 1443-1463. https://doi.org/10.1002/btpr.2173

Forootanfar, H., \& Faramarzi, M. A. (2019). Recent developments in laccase applications for the food industry. Reference module in food science. Elsevier. https://doi.org/ 10.1016/b978-0-08-100596-5.21112-8

Fulin, W. (2017). Ginkgo functional food and preparation method thereof. China Patent CN106579235A Filed. November 7, 2016, and issued. (Accessed 26 April 2017).

Gabdulkhakov, A., Kolyadenko, I., I, Kostareva, O., Mikhaylina, A., Oliveira, P., et al. (2019). Investigations of accessibility of T2/T3 copper center of two-domain laccase from Streptomyces griseoflavus Ac-993. International Journal of Molecular Sciences, 20 (13). https://doi.org/10.3390/ijms20133184. Article 3184.

Gassara-Chatti, F., Brar, S. K., Ajila, C. M., Verma, M., Tyagi, R. D., \& Valero, J. R. (2013). Encapsulation of ligninolytic enzymes and its application in clarification of juice. Food Chemistry, 137(1-4), 18-24. https://doi.org/10.1016/j.foodchem.2012.09.083

Giacobbe, S., Pezzella, C., Lettera, V., Sannia, G., \& Piscitelli, A. (2018). Laccase pretreatment for agrofood wastes valorization. Bioresource Technology, 265, 59-65. https://doi.org/10.1016/j.biortech.2018.05.108

Gottardi, D., Bukvicki, D., Prasad, S., \& Tyagi, A. K. (2016). Beneficial effects of spices in food preservation and safety. Frontiers in Microbiology, 7. https://doi.org/10.3389/ fmicb. 2016.01394. Article 1394.

Guan, Z. B., Luo, Q., Wang, H. R., Chen, Y., \& Liao, X. R. (2018). Bacterial laccases: Promising biological green tools for industrial applications. Cellular and Molecular Life Sciences, 75, 3569-3592. https://doi.org/10.1007/s00018-018-2883-Z

Hou, J.-J., Yang, X. Q., Fu, S. R., Wang, M. P., \& Xiao, F. (2016). Preparation of doublenetwork tofu with mechanical and sensory toughness. International Journal of Food Science and Technology, 51(4), 962-969. https://doi.org/10.1111/ijfs.13043

Huang, X.-C., Yuan, Y.-A., Guo, C.-F., Gekas, V., \& Yue, T.-L. (2015). Alicyclobacillus in the fruit juice industry: Spoilage, detection, and prevention/control. Food Reviews International, 31, 91-124. https://doi.org/10.1080/87559129.2014.974266

Iark, D., Buzzo, A. J. R., Garcia, J. A. A., Correa, V. G., Helm, C. V., Corrêa, R. C. G., et al. (2019). Enzymatic degradation and detoxification of azo dye Congo red by a new laccase from Oudemansiella canarii. Bioresource Technology, 289. https://doi.org/ 10.1016/j.biortech.2019.121655. Article 121655.

Isaschar-Ovdat, S., \& Fishman, A. (2018). Crosslinking of food proteins mediated by oxidative enzymes - a review. Trends in Food Science \& Technology, 72, 134-143. https://doi.org/10.1016/j.tifs.2017.12.011

Jabbari, S., Dabirmanesh, B., Arab, S., Amanlou, M., Daneshjou, S., Gholami, S., et al. (2017). A novel enzyme based SPR-biosensor to detect bromocriptine as an ergoline derivative drug. Sensors and Actuators Part B, Chemical, 240, 519-527. https://doi. org/10.1016/j.snb.2016.08.165
Janusz, G., Pawlik, A., Swiderska-Burek, U., Polak, J., Sulej, J., Jarosz-Wilkołazka, A., et al. (2020). Laccase properties, physiological functions, and evolution. International Journal of Molecular Sciences, 21(3). https://doi.org/10.3390/ijms21030966. Article 966.

Jiang, J., Ye, W., Liu, L., Wang, Z., Fan, Y., Saito, T., et al. (2017). Cellulose nanofibers prepared using the TEMPO/laccase/ $\mathrm{O}_{2}$ system. Biomacromolecules, 18(1), 288-294. https://doi.org/10.1021/acs.biomac.6b01682

Jinfang, H., \& Yongxing, C. (2019). Patent No CN110477338A. Reitered from. https://pat ents.google.com/patent/CN110477338A/en?oq=CN110477338A.

Kadri, T., Rouissi, T., Brar, S. K., Cledon, M., Sarma, S., \& Verma, M. (2017). Biodegradation of polycyclic aromatic hydrocarbons (PAHs) by fungal enzymes: A review. Journal of Environmental Sciences, 51, 52-74. https://doi.org/10.1016/j. jes.2016.08.023

Kamani, H., Safari, G. H., Asgari, G., \& Ashrafi, S. D. (2018). Data on modeling of enzymatic elimination of Direct Red 81 using response surface methodology. Data in Brief, 18, 80-86. https://doi.org/10.1016/j.dib.2018.03.012

Karaki, N., Aljawish, A., Muniglia, L., Bouguet-Bonnet, S., Leclerc, S., Paris, C., et al. (2017). Functionalization of pectin with laccase-mediated oxidation products of ferulic acid. Enzyme and Microbial Technology, 104, 1-8. https://doi.org/10.1016/j. enzmictec.2017.05.001

Khalighi, S., Berger, R. G., \& Ersoy, F. (2020a). Cross-linking of wheat bran arabynoxylan by fungal laccases yields firm gels. Processes, 8(1), 36-51. https://doi.org/10.3390/ pr8010036

Khalighi, S., Berger, R. G., \& Ersoy, F. (2020b). Cross-linking of fibrex gel by fungal laccase: Gel rheological and structured characteristics. Processes, 8(1), 16-31. https://doi.org/10.3390/pr8010016

Kudanga, T., Nemadziva, B., \& Roes-Hill, M. L. (2017). Laccase catalysis for the synthesis of bioactive compounds. Applied Microbiology and Biotechnology, 101, 13-33. https:// doi.org/10.1007/s00253-016-7987-5

Kun, C., Ling, M., Tianqi, L., Xi, W., \& Xindi, W. (2019). Patnt No CN110100946A. Reitered from. https://patents.google.com/patent/CN110100946A/en?oq=CN1101 00946A.

Legerská, B., Chmelová, D., \& Ondrejovič, M. (2016). Degradation of synthetic dyes by laccases - a mini-review. Nova Biotechnologica et Chimica, 15(1), 90-106. https://doi. org/10.1515/nbec-2016-0010

Lepore, M., \& Portaccio, M. (2017). Optical detection of different phenolic compounds by means of a novel biosensor based on sol-gel immobilized laccase. Biotechnology and Applied Biochemistry, 64(6), 782-792. https://doi.org/10.1002/bab.1551

Lettera, V., Pezzella, C., Cicatiello, P., Piscitelli, A., Viacobelli, V. G., Galano, E., et al. (2016). Efficient immobilization of a fungal laccase and its exploitation in fruit juice clarification. Food Chemistry, 196, 1272-1278. https://doi.org/10.1016/j. foodchem.2015.10.074

Li, K., Guan, G., Zhu, J., Wu, H., \& Sun, Q. (2019). Antibacterial activity and mechanism of a laccase-catalyzed chitosan-gallic acid derivative against Escherichia coli and Staphylococcus aureus. Food Control, 96, 234-243. https://doi.org/10.1016/j. foodcont.2018.09.021

Liguori, R., \& Faraco, V. (2016). Biological processes for advancing lignocellulosic waste biorefinery by advocating circular economy. Buoresource Technology, 215, 13-20. https://doi.org/10.1016/j.biortech.2016.04.054

Li, M., Karboune, S., Liu, L., Light, K., L'Hocine, L., Achouri, A., et al. (2021). Combining phenolic grafting and laccase-catalyzed cross-linking: Effects on structures, technofunctional properties and human immunoglobulin E binding capacity of egg white proteins. Food Chemistry, 355. https://doi.org/10.1016/j foodchem.2021.129587. article 129587.

Li, X., Li, S., Liang, X., McClements, D. J., Liu, X., \& Liu, F. (2020). Applications of oxidases in modification of food molecules and colloidal systems: Laccase, peroxidase and tyrosinase. Trends in Food Science \& Technology, 103, 78-93. https:// doi.org/10.1016/j.tifs. 2020.06.014

Lineback, D. R., Coughlin, J. R., \& Stadler, R. H. (2012). Acrylamide in foods: A review of the science and future considerations. Annual Review of Food Science and Technology, 3, 15-35. https://doi.org/10.1146/annurev-food-022811-101114

Linlin, C., Song, Y., Li, L., Huiyan, M., \& Hongyu, D. (2017). Patent No CN106509584. Retrieved from https://patents.google.com/patent/CN106509584A/en?oq=CN 106509584.

Liu, N., Ni, S., Ragauskas, A. J., Meng, X., Hao, N., \& Fu, Y. (2018). Laccase-mediated functionalization of chitosan with 4-hexyloxyphenol enhances antioxidant and hydrophobic properties of copolymer. Journal of Biotechnology, 269, 8-15. https:// doi.org/10.1016/j.jbiotec.2018.01.015

Loi, M., Quintieri, L., Fanelli, F., Caputo, L., \& Mulè, G. (2018). Application of a recombinant laccase-chlorogenic acid system in protein crosslink and antioxidant properties of the curd. Food Research International, 106, 763-770. https://doi.org/ 10.1016/j.foodres. 2018.01.050

Longfang, R., Yongxia, Z., Taotao, Q., Xudong, G., \& Ying, H. (2018). Patent No CN108676108A. Reitered from. https://patents.google.com/patent/CN108676108 A/en?oq $=$ CN108676108A + .

Lou, C., Jing, T., Tian, J., Zheng, Y., Zhang, J., Dong, M., et al. (2019). 3-Dimensional graphene $/ \mathrm{Cu} / \mathrm{Fe}_{3} \mathrm{O}_{4}$ composites: Immobilized laccase electrodes for detecting bisphenol A. Journal of Materials Research, 34(17), 2964-2975. https://doi.org/ 10.1557/jmr. 2019.248

Lú-Chau, T. A., Martínez-Patiño, J. C., Gullón, B., García-Torreiro, M., Moreira, M. T., Lema, J. M., et al. (2018). Scale-up and economic analysis of the production of ligninolytic enzymes from a side-stream of the organosolv process. Journal of Chemical Technology \& Biotechnology, 93, 3125-3134. https://doi.org/10.1002/ jctb.5664

Lv, L., Tian, S., Ahmed, I., Pavase, T. R., Lin, H., Xu, L., et al. (2019). Effect of laccasecatalyzed cross-linking on the structure and allergenicity of Paralichthys olivaceus 
parvalbumin mediated by propyl gallate. Food Chemistry, 297. https://doi.org/ 10.1016/j.foodchem.2019.124972. Article 124972.

Ma, M. M., \& Mu, T. H. (2016). Modification of deoiled cumin dietary fiber with laccase and cellulose under high hydrostatic pressure. Carbohydrate Polymers, 136, 87-94. https://doi.org/10.1016/j.carbpol.2015.09.030

Manavalan, T., Manavalan, A., Thangavelu, K. P., \& Heese, K. (2013). Characterization of optimized production, purification and application of laccase from Ganoderma lucidum. Biochemical Engineering Journal, 70, 106-114. https://doi.org/10.1016/j. bej.2012.10.007

Manhivi, V. E., Amonsou, E. O., \& Kudanga, T. (2018). Laccase-mediated crosslinking of gluten-free amadumbe flour improves rheological properties. Food Chemistry, 264, 157-163. https://doi.org/10.1016/j.foodchem.2018.05.017

Mate, D. M., \& Alcalde, M. (2015). Laccase engineering: From rational design to directed evolution. Biotechnology Advances, 33(1), 25-40. https://doi.org/10.1016/j. biotechadv.2014.12.007

Mate, D. M., \& Alcalde, M. (2016). Laccase: A multi-purpose biocatalyst at the forefront of biotechnology. Microbial Biotechnology, 10(6), 1457-1467. https://doi.org/ 10.1111/1751-7915.12422

Mayolo-Deloisa, K., González-González, M., \& Rito-Palomares, M. (2020). Laccases in food industry: Bioprocessing, potential industrial and biotechnological applications. Frontiers in Bioengineering and Biotechnology, 8, 222-230. https://doi.org/10.3389/ fbioe.2020.00222

Medina-Plaza, C., Saja, J. A., Fernandez-Escudero, J. A., Barajas, E., Medrano, G., \& Rodriguez-Mendez, M. L. (2016). Array of biosensors for discrimination of grapes according to grape variety, vintage and ripeness. Analytica Chimica Acta, 947, 16-22. https://doi.org/10.1016/j.aca.2016.10.032

Mehrabian, F., Kamani, H., Safari, G. H., Asgari, G., \& Ashrafi, S. D. (2018). Direct Blue 71 removal from aqueous solution by laccase-mediated system. A dataset. Data in Brief, 19, 437-443. https://doi.org/10.1016/j.dib.2018.05.056

Mei, L.-P., Feng, J. J., Wu, L., Zhou, J. Y., Chen, J. R., \& Wang, A. J. (2015). Novel phenol biosensor based on laccase immobilized on reduced graphene oxide supported palladium-copper alloyed nanocages. Biosensors and Bioelectronics, 74, 347-352. https://doi.org/10.1016/j.bios.2015.06.060

Mihajlovic, L., Radosavljevic, J., Nordlund, E., Krstic, M., Bohn, T., Smit, J., et al. (2016) Peanut protein structure, polyphenol content and immune response to peanut proteins in vivo are modulated by laccase. Food \& Function, 7(5), 2357-2366. https:// doi.org/10.1039/C5FO01325A

Minussi, R. C., Pastore, G. M., \& Duran, N. (2002). Potential applications of laccase in the food industry. Trends in Food Science \& Technology, 13, 205-216. https://doi.org/ 10.1016/S0924-2244(02)00155-3

Minussi, R. C., Rossi, M., Bologna, L., Rotilio, D., Pastore, G. M., \& Durán, N. (2007) Phenols removal in musts: Strategy for wine stabilization by laccase. Journal of Molecular Catalysis B: Enzymatic, 45(3-4), 102-107. https://doi.org/10.1016/j. molcatb.2006.12.004

Mogharabi, M., \& Faramarzi, M. A. (2014). Laccase and laccase-mediated systems in the synthesis of organic compounds. Advanced Synthesis \& Catalysis, 356, 897-927. https://doi.org/10.1002/adsc.201300960

Mohtar, L. G., Aranda, P., Messina, G. A., Nazareno, M. A., Pereira, S. V., Raba, J., et al. (2019). Amperometric biosensor based on laccase immobilized onto a nanostructured screen-printed electrode for determination of polyphenols in propolis. Microchemical Journal, 144, 13-18. https://doi.org/10.1016/j. microc.2018.08.038

Mokoonlall, A., Pfannstiel, J., Struch, M., Berger, R. G., \& Hinrichs, J. (2016a). Structure modification of stirred fermented milk gel due to laccase-catalysed protein crosslinking in a post-processing step. Innovative Food Science \& Emerging Technologies, 33, 563-570. https://doi.org/10.1016/j.ifset.2015.10.006

Mokoonlall, A., Sykora, L., Pfannstiel, J., Nöbel, S., Weis, J., \& Hinrichs, J. (2016b). A feasibility study on the application of a laccase-mediator system in stirred yoghurt at the pilot scale. Food Hydrocolloids, 60, 119-127. https://doi.org/10.1016/j. foodhyd.2016.03.027

Moreno, A. D., Ibarra, D., Eugenio, M. E., \& Tomás-Pejó, E. (2020). Laccases as versatile enzymes: From industrial uses to novel applications. Journal of Chemical Technology and Biotechnology, 95, 495-512. https://doi.org/10.1002/jctb.6224

Mukesh, Y., Nirmala, S., \& Amit, K. (2018). Microbial laccases in food processing industry: Current status and future perspectives. Research Journal of Biotechnology, 13, 108-113.

Muñiz-Mouro, A., Gullón, B., Lú-Chau, T. A., Moreira, M. T., Lema, J. M., \& Eibes, G. (2018). Laccase activity as an essential factor in the oligomerization of rutin. Catalysts, 8(8). https://doi.org/10.3390/catal8080321. Article 321.

Muñiz-Mouro, A., Oliveira, I. M., Gullón, B., Lú-Chau, T. A., Moreira, M. T., Lema, J. M., et al. (2017). Comprehensive investigation of the enzymatic oligomerization of esculin by laccase in ethanol: water mixtures. RSC Advances, 7(61), 38424-38433. https://doi.org/10.1039/C7RA06972C

Munk, L., Muschiol, J., Li, K., Liu, M., Perzon, A., Meier, S., et al. (2020). Selective enzymatic release and gel formation by cross-linking of feruloylated glucuronoarabinoxylan from corn bran. ACS Sustainable Chemistry \& Engineering, 8(22), 8164-8174. https://doi.org/10.1021/acssuschemeng.0c00663

Munk, L., Sitarz, A. K., Kalyani, D. C., Mikkelsen, J. D., \& Meyer, A. S. (2015). Can laccases catalyze bond cleavage in lignin? Biotechnology Advances, 33(1), 13-24. https://doi.org/10.1016/j.biotechadv.2014.12.008

Narnoliya, L. K., Agarwal, N., Patel, S. N., \& Singh, S. P. (2019). Kinetic characterization of laccase from Bacillus atrophaeus, and its potential in juice clarification in free and immobilized forms. Journal of Microbiology, 57, 900-909. https://doi.org/10.1007/ s12275-019-9170-Z

Navada, K. K., \& Kulal, A. (2019). Enzymatic degradation of chloramphenicol by laccase from Trametes hirsuta and comparison among mediators. International
Biodeterioration \& Biodegradation, 138, 63-69. https://doi.org/10.1016/j. ibiod.2018.12.012

Nazari, M., Kashanian, S., Maleki, N., \& Shahabadi, N. (2019). Laccase immobilized onto graphene oxide nanosheets and electrodeposited gold-cetyltrimethylammonium bromide complex to fabricate a novel catechol biosensor. Bulletin of Materials Science, 42, 51-61. https://doi.org/10.1007/s12034-018-1717-9

Neifar, M., Ellouze-Ghorbel, R., Kamoun, A., Baklouti, S., Mokni, A., Jaouani, A., et al. (2011). Effective clarification of pomegranate juice using laccase treatment optimized by response surface methodology followed by ultrafiltration. Journal of Food Process Engineering, 34(4), 1199-1219. https://doi.org/10.1111/j.17454530.2009.00523.x

Nemadziva, B., Roes-Hill, M. L., Koorbanally, N., \& Kudanga, T. (2018). Small laccasecatalyzed synthesis of a caffeic acid dimer with high antioxidant capacity. Process Biochemistry, 69, 99-105. https://doi.org/10.1016/j.procbio.2018.03.009

Ning, X., Xiao, J., Jianwen, T., Baoyao, W., \& Li, H. (2016). Patent No CN105670010A. Reitered from. https://patents.google.com/patent/CN105670010A/zh.

Nizami, A. S., Rehan, M., Waqas, M., Naqvi, M., Ouda, O. K., Shahzad, K., et al. (2017). Waste biorefineries: Enabling circular economies in developing countries. Bioresource Technology, 241, 1101-1117. https://doi.org/10.1016/j. biortech.2017.05.097

Olivares, B., Martínez, F., Rivas, L., Calderón, C., Munita, J. M., \& Campodonico, P. R. (2018). A Natural deep eutectic solvent formulated to stabilize $\beta$-lactam antibiotics. Scientific Reports, 8, 14900-14912. https://doi.org/10.1038/s41598-018-33148-w

Osma, J. F., Toca-Herrera, J. L., \& Rodríguez-Couto, S. (2011). Cost analysis in laccase production. Journal of Environmental Management, 92(11), 2907-2912. https://doi. org/10.1016/j.jenvman.2011.06.052

Patel, S. K. S., Anwar, M. Z., Kumar, A., Otari, S. V., Pagolu, R. T., Kim, S. Y., et al. (2018). $\mathrm{Fe}_{2} \mathrm{O}_{3}$ yolk-shell particle-based laccase biosensor for efficient detection of 2,6-dimethoxyphenol. Biochemical Engineering Journal, 132, 1-8. https://doi.org/ 10.1016/j.bej.2017.12.013

Patel, N., Shahane, S., Shivam, S., Majumdar, R., \& Mishra, U. (2019). Mode of action, properties, production, and application of laccase: A review. Recent Patents on Biotechnology, 13(1), 19-32. https://doi.org/10.2174/ 1872208312666180821161015

Pezzella, C., Guarino, L., \& Piscitelli, A. (2015). How to enjoy laccases. Cellular and Molecular Life Sciences, 72(5), 923-940. https://doi.org/10.1007/s00018-014-18239

Pogni, R., Baratto, M. C., Sinicropi, A., \& Basosi, R. (2015). Spectroscopic and computational characterization of laccases and their substrate radical intermediates. Cellular and Molecular Life Sciences, 72, 885-896. https://doi.org/10.1007/s00018014-1825-7

Polak, J., \& Jarosz-Wilkolazka, A. (2012). Fungal laccases as green catalysts for dye synthesis. Process Biochemistry, 47(9), 1295-1307. https://doi.org/10.1016/j. procbio.2012.05.006

Polyakov, K. M., Gavryushov, S., Ivanova, S., Fedorova, T. V., Glazunova, O. A., Popov, A. N., et al. (2017). Structural study of the X-ray-induced enzymatic reduction of molecular oxygen to water by Steccherinum murashkinskyi laccase: Insights into the reaction mechanism. Acta Crystallographica Section D: Structura Biology, 73, 388-401. https://doi.org/10.1107/S2059798317003667

Qayum, A., Hussain, M., Li, M., Li, J., Shi, R., Li, T., et al. (2021). Gelling, microstructure and water-holding properties of alpha-lactalbumin emulsion gel: Impact of combined ultrasound pretreatment and laccase cross-linking. Food Hydrocolloids, 110. https:// doi.org/10.1016/j.foodhyd.2020.106122. Article 106122.

Qingjie, S., Jie, Y., Liu, X., Hao, W., Yanfei, W., Wenxiang, L., et al. (2019). Patent No CN109679123A. Reitered from. https://patents.google.com/patent/CN1096791 23A/zh?oq=CN109679123A.

Quanzhong, B. (2017). Patent No CN107190574A. Reitered from. https://patents.google. $\mathrm{com} /$ patent $/ \mathrm{CN} 107190574 \mathrm{~A} / \mathrm{en} ? \mathrm{oq}=\mathrm{CN1} 107190574 \mathrm{~A}+$.

Reano, A. F., Pion, F., Domenek, S., Ducrot, P. H., \& Allais, F. (2016). Chemo-enzymatic preparation and characterization of renewable oligomers with bisguaiacol moieties: Promising sustainable antiradical/antioxidant additives. Green Chemistry, 18(11), 3334-3345. https://doi.org/10.1039/C6GC00117C

Reiss, R., Ihssen, J., Richter, M., Eichhorn, E., Schilling, B., \& Thony-Meyer, L. (2013) Laccase versus laccase-like multi-copper oxidase: A comparative study of similar enzymes with diverse substrate spectra. PloS One, 8(6), Article e65633. https://doi. org/10.1371/journal.pone.0065633. Article.

Renz, H., Allen, K. J., Sicherer, S. H., Sampson, H. A., Lack, G., Beyer, K., et al. (2018). Food allergy. Nature Reviews Disease Primers, 4. https://doi.org/10.1038/ nrdp.2017.98. Article 17098.

Ribeiro, D. S., Henrique, S. M. B., Oliveira, L. S., Macedo, G. A., \& Fleuri, L. F. (2010). Enzymes in juice processing: A review. International Journal of Food Science and Technology, 45(4), 635-641. https://doi.org/10.1111/j.1365-2621.2010.02177.x

Rifai, L., \& Saleh, F. A. (2020). A review on acrylamide in food: Occurrence, toxicity, and mitigation strategies. International Journal Of Toxicology, 39, 93-102. https://doi. org/10.1177/1091581820902405

Rodríguez-Delgado, M. M., Alemán-Nava, G. S., Rodríguez-Delgado, J. G., DieckAssad, G., Martínez-Chapa, S. O., Barceló, D., et al. (2015). Laccase-based biosensors for detection of phenolic compounds. Trends in Analytical Chemistry, 74, 21-45. https://doi.org/10.1016/j.trac.2015.05.008

Rola, B., Karaskiewicz, M., Majdecka, D., Mazur, I., Bilewicz, R., Rogalsk, J., et al. (2013). Scale up of Cerrena unicolor laccase production. Journal of the Faculty of Agriculture, Kyushu University, 58, 231-238. https://doi.org/10.5109/27352

Roth, S., \& Spiess, A. C. (2015). Laccases for biorefinary applications: A critical review on challenges and perspectives. Bioprocess and Biosystems Engineering, 38, 2285-2313. https://doi.org/10.1007/s00449-015-1475-7 
Rottmann, E., Hauke, K. F., Krings, U., \& Berger, R. G. (2021). Enzymatic acrylamide mitigation in French fries - an industrial-scale case study. Food Control, 123. https:// doi.org/10.1016/j.foodcont.2020.107739. Article 107739.

dos Santos, J. C. S., Barbosa, O., Ortiz, C., Berenguer-Murcia, A., Rodrigues, R. C., \& Fernandez-Lafuente, R. (2015). Importance of the support properties for immobilization or purification of enzymes. ChemCatChem Reviews, 7, 2413-2432. https://doi.org/10.1002/cctc. 201500310

Sato, A. C. K., Perrechil, F. A., Costa, A. A. S., Santana, R. C., \& Cunha, R. L. (2015). Cross-linking proteins by laccase: Effects on the droplet size and rheology of emulsions stabilized by sodium caseinate. Food Research International, 75, 244-251. https://doi.org/10.1016/j.foodres.2015.06.010

Schirmann, J. G., Dekker, R. F. H., Borsato, D., \& Barbosa-Dekker, A. M. (2018). Selective control for the laccase-catalyzed synthesis of dimers from 2,6-dimethoxyphenol: Optimization of 3,3',5,5'-tetramethoxy-biphenyl-4,4'-diol synthesis using factorial design, and evaluation of its antioxidant action in biodiesel. Applied Catalysis A: General, 555, 88-97. https://doi.org/10.1016/j.apcata.2018.02.015

Schroeder, M., Pollinger-Zierler, M., Aichernig, N., Siegmund, N., Siegmund, B., \& Guebitz, G. M. (2008). Enzymatic removal of off-flavors from apple juice. Journal of Agricultural and Food Chemistry, 56, 2485-2489. https://doi.org/10.1021/ jf073303m

Sekretaryova, A., Jones, S. M., \& Solomon, E. I. (2019). $\mathrm{O}_{2}$ reduction to water by high potential multicopper oxidases: Contributions of the T1 copper site potential and the local environment of the trinuclear copper cluster. Journal of the American Chemical Society, 141(28), 11304-11314. https://doi.org/10.1021/jacs.9b05230

Selinheimo, E., Kruus, K., Buchert, J., Hopia, A., \& Autio, K. (2006). Effects of laccase, xylanase and their combination on the rheological properties of wheat doughs. Journal of Cereal Science, 43(2), 152-159. https://doi.org/10.1016/j.jcs.2005.08.007

Senthivelan, T., Kanagaraj, J., \& Panda, R. C. (2016). Recent trends in fungal laccase for various industrial applications: An eco-friendly approach - a review. Biotechnology and Bioprocess Engineering, 21, 19-38. https://doi.org/10.1007/s12257-015-0278-7

Sharma, A., Jain, K. K., Jain, A., Kidwai, M., \& Kuhad, R. C. (2018). Bifunctional in vivo role of laccase exploited in multiple biotechnological applications. Applied Microbiology and Biotechnology, 102, 10327-10343. https://doi.org/10.1007/ s00253-018-9404-8

Sheldon, R. A. (2016). Biocatalysis and biomass conversion in alternative reaction media. Chemistry-A European Journal, 22, 12984-12999. https://doi.org/10.1002/ chem. 201601940

Shim, E., Noro, J., Cavaco-Paulo, A., Silva, C., \& Kim, H. R. (2019). Effect of additives on the in situ laccase-catalyzed polymerization of aniline onto bacterial cellulose. Frontiers in Bioengineering and Biotechnology, 7, 264-273. https://doi.org/10.3389/ fbioe.2019.00264

Silva, S. B., Krolicka, M., van den Broek, L. A. M., Frissen, A. E., \& Boeriu, C. G. (2018) Water-soluble chitosan derivatives and pH-responsive hydrogels by selective C-6 oxidation mediated by TEMPO-laccase redox system. Carbohydrate Polymers, 186, 299-309. https://doi.org/10.1016/j.carbpol.2018.01.050

Solomon, E. I. (2016). Dioxygen binding, activation, and reduction to $\mathrm{H}_{2} \mathrm{O}$ by $\mathrm{Cu}$ enzymes. Inorganic Chemistry, 55(13), 6364-6375. https://doi.org/10.1021/acs. inorgchem.6b01034

Solomon, E. I., Augustine, A. J., \& Yoon, J. (2008). $\mathrm{O}_{2}$ reduction to $\mathrm{H}_{2} \mathrm{O}$ by the multicopper oxidases. Dalton Transactions, 14(30), 3921-3932. https://doi.org/ 10.1039/B800799C

Songulashvili, G., Spindler, D., Jimenéz-Tobón, G. A., Jaspers, C., Kerns, G., \& Penninckx, M. J. (2015). Production of a high level of laccase by submerged fermentation at 120-L scale of Cerrena unicolor C-139 grown on wheat bran. Comptes Rendus Biologies, 338, 121-125. https://doi.org/10.1016/j.crvi.2014.12.001

Stanic, D., Monogioudi, E., Dilek, E., Radosavljevic, J., Atanaskovic-Markovic, M., Vuckovic, O., et al. (2010). Digestibility and allergenicity assessment of enzymatically crosslinked beta-casein. Molecular Nutrition \& Food Research, 54 1273-1284. https://doi.org/10.1002/mnfr.200900184

Struch, M., Krahe, N. K., Linke, D., Mokoonlall, A., Hinrichs, J., \& Berger, R. G. (2015) Laccase-catalysed cross-linking of a yoghurt-like model system made from skimmed milk with added food-grade mediators. International Dairy Journal, 49, 89-94. https://doi.org/10.1016/j.idairyj.2015.04.002

Struch, M., Krahe, N. K., Linke, D., Mokoonlall, A., Hinrichs, J., \& Berger, R. G. (2016) Dose dependent effects of a milk ion tolerant laccase on yoghurt gel structure. $L W T$ Food Science and Technology, 65, 1144-1152. https://doi.org/10.1016/j. lwt.2015.10.004

Su, J., Fu, J., Wang, Q., Silva, C., \& Cavaco-Paulo, A. (2018). Laccase: A green catalyst for the biosynthesis of poly-phenols. Critical Reviews in Biotechnology, 38(2), 294-307. https://doi.org/10.1080/07388551.2017.1354353

Taheri-Kafrani, A., Kharazmi, S., Nasrollahzadeh, M., Soozanipour, A., Ejeian, F., Etedali, P., et al. (2020). Recent developments in enzyme immobilization technology for hig, R.S.h-throughput processing in food industries. Critical Reviews in Food Science and Nutrition. (in press) https://doi.org/10.1080/10408398.2020.1793726.

Taihua, M., Mengmei, M. A., Miao, Z., Jingwang, C., \& Hongnan, S. (2015a). Patent No CN104757562A. Retrieved from https://patents.google.com/patent/CN1035985 96A/fi.

Taihua, M., Xingli, L., Miao, Z., Hongnan, S., Jingwang, C., \& Xiaofeng, D. (2015b). Patent No CN104255853A. Retrieved from https://patents.google.com/patent /CN104255853A/zh.

Takeshi, S., Maiko, T., \& Michiyuki, T. (2016). Patent No JP2016198007A. Reitered from. https://patents.google.com/patent/JP2016198007A/en?oq=JP2016198007A.

Tanrioven, D., \& Eksi, A. (2005). Phenolic compounds in pear juice from different cultivars. Food Chemistry, 93(1), 89-93. https://doi.org/10.1016/j. foodchem.2004.09.009
Tantoush, Z., Stanic, D., Stojadinovic, M., Ognjenovic, J., Mihaylovic, L., AtanaskovicMarkovic, M., et al. (2011). Digestibility and allergenicity of $\beta$-lactoglobulin following laccase-mediated cross-linking in the presence of sour cherry phenolics. Food Chemistry, 125, 84-91. https://doi.org/10.1016/j.foodchem.2010.08.040

Thakur, K., Kalia, S., Pathania, D., Sharma, N., \& Schauer, C. L. (2016). Surface functionalization of lignin constituent of coconut fibers via laccase-catalyzed biografting for development of antibacterial and hydrophobic properties. Journal of Cleaner Production, 113, 176-182. https://doi.org/10.1016/j.jclepro.2015.11.048

Tian, X., Wang, Y., Duan, S., Hao, Y., Zhao, K., Li, Y., et al. (2021). Evaluation of a novel nano-size collagenous matrix film cross-linked with gallotannins catalyzed by laccase. Food Chemistry, 351. https://doi.org/10.1016/j.foodchem.2021.129335. article 129335

Tisma, M., Znidarsic-Plazi, P., Vasic-Racki, D., \& Zelic, B. (2012). Optimization of laccase production by Trametes versicolor cultivated on industrial waste. Applied Biochemistry and Biotechnology, 166, 36-46. https://doi.org/10.1007/s12010-011-9401-1

Tulek, A., Ersin, E., Cakar, M. M., Aydin, D., Yilmazcan, O., \& Binay, B. (2020) Optimisation of the production and bleaching process for a new laccase from Madurella mycetomatis, expressed in Pichia pastoris: From secretion to yielding prominent. Molecular Biotecnology, 63(1), 24-39. https://doi.org/10.1007/s12033020-00281-9

Upadhyay, P., Shrivastava, R., \& Agrawal, P. K. (2016). Bioprospecting and biotechnological applications of fungal laccase. 3 Biotech, 6(1), 15-27. https://doi. org/10.1007/s13205-015-0316-3

Vallecillos, L., Sadef, Y., Borrull, F., Pocurull, E., \& Bester, K. (2017). Degradation of synthetic fragrances by laccase-mediated system. Journal of Hazardous Materials, 334, 233-243. https://doi.org/10.1016/j.jhazmat.2017.04.003

Verrastro, M., Cicco, N., Crispo, F., Morone, A., Dinescu, M., Dumitru, M., et al. (2016). Amperometric biosensor based on laccase immobilized onto a screen-printed electrode by matrix assisted pulsed laser evaporation. Talanta, 154, 438-445. https://doi.org/10.1016/j.talanta.2016.03.072

Viswanath, B., Rajesh, B., Janardhan, A., Kumar, A. P., \& Narasimha, G. (2014). Fungal laccases and their applications in bioremediation. Enzyme Research, 21. https://doi. org /10.1155/2014/163242. Article 163242.

Vuillemin, M. E., Michaux, F., Adam, A. A., Linder, M., Muniglia, L., \& Jasniewski, J. (2020). Physicochemical characterizations of gum Arabic modified with oxidation products of ferulic acid. Food Hydrocolloids, 107. https://doi.org/10.1016/j. foodhyd.2020.105919. Article 105919.

Wang, J., Feng, F., Jia, W., Chang, S., Li, S., \& Li, Y. (2015). Lignin engineering through laccase modification: A promising field for energy plant improvement. Biotechnology for Biofuels, 8, 145-156. https://doi.org/10.1186/s13068-015-0331-y

Wang, F., Guo, C., \& Liu, C.-Z. (2013). Immobilization of Trametes versicolor cultures for improving laccase production in bubble column reactor intensified by sonication. Journal of Industrial Microbiology and Biotechnology, 40, 141-150. https://doi.org/ 10.1007/s10295-012-1214-x

Wang, K. F., Hu, J. H., Guo, C., \& Liu, C. Z. (2016). Scale-up laccase production from Trametes versicolor stimulated by vanillic acid. Bioprocess and Biosystems Engineering, 39, 1041-1049. https://doi.org/10.1007/s00449-016-1582-0

Wang, F., Ma, A.-Z., Guo, C., Zhuang, G.-Q., \& Liu, C.-Z. (2013). Ultrasound-intensified laccase production from Trametes versicolor. Ultrasonics Sonochemistry, 20, 118-124. https://doi.org/10.1016/j.ultsonch.2012.05.003

Wang, F., Owusu-Fordjour, M., Xu, L., Ding, Z., \& Gu, Z. (2020). Immobilization of laccase on magnetic chelator nanoparticles for apple juice clarification in magnetically stabilized fluidized bed. Frontiers in Bioengineering and Biotechnology, 8, 589-602. https://doi.org/10.3389/fbioe.2020.00589

Wang, F., Xu, L., Zhao, L., Ding, Z., Ma, H., \& Terry, N. (2019). Fungal laccase production from lignocellulosic agricultural wastes by solid-state fermentation: A review. Microorganisms, 7(12), 665-680. https://doi.org/10.3390/microorganisms7120665

Wang, Y.-R., Yang, Q., Li-Sha, J. Y.-J., \& Chen, H.-Q. (2021). Structural, gelation properties and microstructure of rice glutelin/sugar beet pectin composite gels: Effects of ionic strengths. Food Chemistry, 346. https://doi.org/10.1016/j. foodchem.2020.128956. article 128956.

Wang, D., Zhu, H., Li, M., Song, X., Yan, H., Yu, J., et al. (2018). An efficient method for the preparative separation and isolation of ginkgolic acids from the sarcotesta of Ginkgo biloba L by pH-zone-refining countercurrent chromatography coupled with inner-recycling mode. Industrial Crops and Products, 126, 69-75. https://doi.org/ 10.1016/j.indcrop.2018.09.034

Xu, P., Zheng, G. W., Zong, M. H., Li, N., \& Lou, W.-Y. (2017). Recent progress on deep eutectic solvents in biocatalysis. Bioresource Bioprocessing, 4(34-52). https://doi.org/ 10.1186/s40643-017-0165-5, 4:34.

Yang, J., Li, W., Ng, T. B., Deng, X., Lin, J., \& Ye, X. (2017). Laccases: Production, expression regulation, and applications in pharmaceutical biodegradation. Frontiers in Microbiology, 8, 832-856. https://doi.org/10.3389/fmicb.2017.00832

Yang, J., Sun, J., Zheng, M., Lu, Z., Lu, F., \& Zhang, C. (2018). Preparation of ferulic acidgrafted chitosan using recombinant bacterial laccase and its application in mango preservation. RSC Advances, 8, 6759-6767. https://doi.org/10.1039/C7RA12696D

Yanxiang, G., \& Di, W. (2018). Patent No CN108719999. Reitered from. https://patents. google.com/patent/CN108719999A/en?oq=CN108719999.

Yin, L., Ye, J., Kuang, S., Guan, Y., \& You, R. (2017). Induction, purification, and characterization of a thermo and $\mathrm{pH}$ stable laccase from Abortiporus biennis $\mathrm{J} 2$ and its application on the clarification of litchi juice. Journal Bioscience, Biotechnology, and Biochemistry, 81(5), 1033-1040. https://doi.org/10.1080/09168451.2017.1279850

Zerva, A., Simic, S., Topakas, E., \& Nikodinovic-Runic, J. (2019). Applications of microbial laccases: Patent review of the past decade (2009-2019). Catalysts, 9(12), 1023-1049. https://doi.org/10.3390/catal9121023 
Zhanmei, J., Liang, Z., Chunyan, W., \& Xiangying, Y. (2018). Patent No CN108719575A Reitered from. https://patents.google.com/patent/CN108719575A/en?oq=CN10871 9575A.

Zhou, W., Zhang, W., \& Cai, Y. (2021). Laccase immobilization for water purification: A comprehensive review. Chemical Engineering Journal, 403. https://doi.org/10.1016 j.cej.2020.126272. Article 126272.
Zrinski, I., Pungjunun, K., Martinez, S., Savašnik, J., Stanković, D., Kalcher, K., et al. (2020). Evaluation of phenolic antioxidant capacity in beverages based on laccase immobilized on screen-printed carbon electrode modified with graphene nanoplatelets and gold nanoparticles. Microchemical Journal, 152. https://doi.org/ 10.1016/j.microc.2019.104282. Article 104282. 